\title{
Evolution of upwelling systems coupled to the long-term variability in sea surface temperature and Ekman transport
}

\author{
Paula C. Pardo ${ }^{1}$, Xosé A. Padín ${ }^{1}$, Miguel Gilcoto ${ }^{1}$, Luis Farina-Busto ${ }^{2}$, Fiz F. Pérez ${ }^{1, *}$ \\ ${ }^{1}$ Instituto de Investigaciones Marinas, CSIC, 36208 Vigo, Spain \\ ${ }^{2}$ Facultade de Ciencias do Mar, Universidade de Vigo, Campus de Lagoas-Marcosende, 36310 Vigo, Spain
}

\begin{abstract}
In the early 1990s it was hypothesized that the global warming process would produce an increase in sea-land temperature gradients and, subsequently, enhance the wind patterns responsible for coastal upwelling. Hence, an increase in the intensity of coastal upwelling was expected in the main upwelling ecosystems around the world. However, recently published analyses of the evolution of coastal upwelling processes have shown contradictory evidence. For this reason, time series of sea-surface temperature (SST) and the upwelling index $I_{\mathrm{w}}$ extracted from the NCEP/NCAR reanalysis project database and covering the last 6 decades were studied. The time series analyses focused on the northern part of the Canary Current System and included comparisons with upwelling systems off NW Africa, California, Benguela and Peru. Climatic indices, including the Atlantic Multidecadal Oscillation, Eastern Atlantic Pattern, Interdecadal Pacific Oscillation Index and North Atlantic Oscillation, were investigated to explain the variability found in the NCEP/NCAR time series. A general sea-surface warming and weakening of the upwelling intensity in the Iberian/Canary and NW African regions were found and these have intensified in the last 4 decades. These trends were clearly observed in winter and autumn for both regions, and a weakening in the upwelling intensity was also detected in summer in the NW African region. The North Atlantic Oscillation and the Eastern Atlantic Pattern indices correlated with both SST and $I_{\mathrm{w},}$ particularly in winter and spring, and also with both the Iberian/Canary and NW African regions. No clear trend was found for the California region, while, conforming to the hypothesis, the Benguela region exhibited enhancement of upwelling, but only slight sea-surface warming. In contrast, the Peru region indicated a weakening of upwelling accompanied by marginal sea-surface warming.
\end{abstract}

KEY WORDS: Coastal upwelling - Global warming - Temperature trends · Ocean-atmosphere coupling $\cdot$ Interannual variability

\section{INTRODUCTION}

Coastal upwelling develops on the eastern margins of subtropical gyres in the Atlantic and the Pacific Oceans when predominant, along-shore winds drive the surface Ekman transport offshore. The surface water from the coast has to be supplied from below, and, thus, cooler, nutrient-rich water ascends into the coastal photic layer along a narrow region close to the coast (Wooster et al. 1976, Tomczak \& Godfrey 2003, Arístegui et al. 2009). The stimulation of high phytoplankton production, the base of the food chain, by these nutrient pulses renders coastal upwelling ecosystems the most productive large marine ecosystems in the world's oceans. In fact, coastal upwelling, despite constituting $<1 \%$ of the world's oceans by area, accounts for $\sim 20 \%$ of the global fish catch (Pauly \& Christensen 1995). Furthermore, coastal upwelling systems are also important in terms of atmosphere-ocean $\mathrm{CO}_{2}$ exchange, carbon recycling and export offshore. The 4 large eastern boundary upwelling ecosystems (EBUEs) are those associated with the Canary, California, Humboldt and Benguela Currents (Chavez \& Messié 2009). 
Any change in the wind pattern can modify the intensity of upwelling over different time scales. These changes have a strong influence on the biogeochemistry, productivity and fish populations of these ecosystems and, therefore, have serious socio-economic consequences for the region (Bakun 1990, Di Lorenzo et al. 2005, Lemos \& Sansó 2006, Barth et al. 2007, McGregor et al. 2007, Gómez-Gesteira et al. 2008a, Belkin 2009, Pérez et al. 2010).

The response of the EBUEs and the associated impact under a global climate change scenario have motivated numerous studies over different time periods. These recent analyses covering different aspects of the variability in EBUEs with respect to global climate change are very controversial. In general terms, Bakun (1990) argued that an increase in global temperature would cause an enhancement of coastal upwelling. The same author found the expected long-term intensification of upwelling-favourable winds over the west coast of the Iberian Peninsula (Canary Current System) from 1948 to 1979. McGregor et al. (2007) supported Bakun's scheme from measures of alkenone contents in calcifier organisms in sediment cores at Cape Ghir (Canary Current System). Using alkenones as a proxy for sea-surface temperature (SST), they obtained a cooling of $0.5^{\circ} \mathrm{C}$ during the 20th century, which was associated with an increase of the coastal upwelling. Nevertheless, Lemos \& Pires (2004) and Lemos \& Sansó (2006) found opposite results in the same EBUE and during similar periods of time, namely, 1940-2000 and 1901-2000, respectively. They observed that a significant weakening of the upwelling-favourable winds characterized Iberian upwelling, together with long-term warming in coastal waters. Pérez et al. (2010) reported that the upwelling index for the west coast of the Iberian Peninsula decreased from 1967 to 2006, and GómezGesteira et al. (2008a) noted a long-term decrease in the upwelling intensity, with a quasi-bidecadal oscillation between the latitudes of 18.5 and $36.5^{\circ} \mathrm{N}$ (Canary Current System).

In addition to the Canary Current System, other wellstudied EBUEs, such as the California Current System, showed contradictory results in relation to the longterm variability in coastal upwelling. Schwing \& Mendelssohn (1997), Schwing et al. (1998) and Mendelssohn \& Schwing (2002) used state-space models to separate seasonal signals in the dataset from long-term trends. They found that, for some locations in the California Current System $\left(32-40^{\circ} \mathrm{N}\right)$, the increase of coastal upwelling in the favoured season could be linked to the opposite trends in the long-term changes of SST, supporting the arguments of Bakun. Nevertheless, for locations north of $40^{\circ} \mathrm{N}$, the winds favourable to upwelling weaken and coastal waters warm up, and, south of $30^{\circ} \mathrm{N}$, the reinforcement of winds is not reflected in the coastal SST. Di Lorenzo et al. (2005) also highlighted the strengthening of upwelling-favourable winds in conjunction with a long-term warming trend in the SSTs of the California Current System based on observational data and model experiments. However, their model results pointed to a net reduction in the upwelling of subsurface waters to the sea surface. On the contrary, Barth et al. (2007) showed biochemical anomalies in the year 2005 associated with delayed and stronger seasonal upwelling; this is consistent with the hypothesis that global warming is a driver of stronger upwelling (Bakun 1990). These disagreements, which could arise from an error in data management (Lemos \& Sansó 2006, Bakun et al. 2009), provoked further studies, approaching the issue with both broad and detailed analyses (Arístegui et al. 2009, Chavez \& Messié 2009, Pérez et al. 2010). In any case, regional and global changes in EBUEs still present important challenges.

In the present paper, we summarize the temporal trends in SSTs and the upwelling index ( $I_{\mathrm{w} i}$ Bakun 1973) and the relation between them in the Iberian/ Canary region (northern part of the Canary Current System) during the last 6 decades from the NCEP/ NCAR reanalysis project (Kalnay et al. 1996). Analysis of the coupling between long-term warming trends and fluctuations in upwelling intensity was extended to the southern part of the Canary Current System and to 3 other large EBUEs, in order to identify any general pattern on both spatial and temporal scales. The changes in the major modes of climate variability explaining the overall meteorological situation in the different EBUEs were compared with the observed changes in SST and $I_{\mathrm{w}}$.

\section{DATA AND METHODS}

\subsection{Study regions and EBUEs}

The analyses of large-scale temporal variability in SSTs and $I_{\mathrm{w}}$ in coastal upwelling are focused on the northern part of the Canary Current System. The upwelling region associated with the Canary Current System $\left(12-43^{\circ} \mathrm{N}\right)$ is dynamically complex, and it can be divided into sub-regions according to its circulation, physical environment and shelf dynamics (Arístegui et al. 2009). In general, it can be separated into 2 distinct areas: the Iberian coast and the Northwest African coast (Arístegui et al. 2004). The Gulf of Cádiz, entrance to the Mediterranean, weakens the connectivity between these coasts. The presence of the Canary Archipelago, close to the NW African coast affects the main flow of the Canary Current and introduces mesoscale variability (Arístegui et al. 1994, Barton 1998). Thus, the region 
covering the Iberian coast to the Canary Archipelago was selected for the present study (Iberian/Canary region, $26^{\circ}$ to $43^{\circ} \mathrm{N}$ ) to deal in depth with the contradictory evidence on long-term coastal upwelling trends (Bakun 1990, McGregor et al. 2007, Gómez-Gesteira et al. 2008b, Pérez et al. 2010). The subject is investigated through a detailed intra-regional analysis of the longterm changes observed within the Iberian/Canary region. Subsequently, the analyses are extended southward along the NW African coast (NW African region, $10.5^{\circ}$ to $23.8^{\circ} \mathrm{N}$ ). In order to obtain an overall picture of the long-term changes in the largest EBUEs, those associated with the Benguela Current System in the South Atlantic (Benguela region, $16.2^{\circ}$ to $29.5^{\circ} \mathrm{S}$ ), the California Current System (California region, $33.3^{\circ}$ to $44.8^{\circ} \mathrm{N}$ ) and the Humboldt Current System (Peru region, $4.8^{\circ}$ to $16.2^{\circ} \mathrm{S}$ ) in the Pacific are included in the analysis as well.

\subsection{Data set and methods}

SST and the components of wind velocity at $10 \mathrm{~m}$ above the sea surface were taken from the NCEP/ NCAR reanalysis project (hereafter, NCEP; Kalnay et al. 1996). The NCEP data were obtained from the website of the NOAA-CIRES Climate Diagnostics Center, Boulder, CO, USA (www.cdc.noaa.gov/). These NCEP variables are supplied on a T62 Gaussian grid, corresponding to $\sim 1.9^{\circ}$ in both latitude and longitude (192 longitude $\times 94$ latitude equally spaced grid points). These data cover the time period from 1948 until present, although there are concerns regarding the quality of the reanalysis in the pre-satellite period (Kalnay et al. 1996, Hines et al. 2000). Fields consist of instantaneous values at the end of the $6 \mathrm{~h}$ period, comprising a total of 90508 outputs for our dataset from 1948 until the end of 2009. The NCEP data result from a hindcast, using observations from a number of sources and a frozen data assimilation system. The co-location of the $6 \mathrm{~h}$ NCEP fields of SST and meridional and zonal wind velocity in the 5 separated regions (Fig. 1) were carried out directly at the grid nodes of the NCEP sigma coordinate system without any spatial interpolation. The grid nodes were those selected as the closest to the coastline, delimited by the land NCEP mask. Between 6 and 8 grid nodes were selected for each region. Their locations and some $I_{\mathrm{w}}$ and SST statistics are given in Table 1 and Fig. 1.

\subsection{Estimates of Ekman transport}

Wind-driven coastal upwelling is caused by the along-shore component of wind stress $\left(\tau_{y}\right)$, which gen- erates both offshore (upwelling) and onshore (downwelling) Ekman transport $\left(I_{\mathrm{w}}\right)$ at the coast. $I_{\mathrm{w}}$ can be estimated by Bakun's (1973) method:

$$
I_{\mathrm{w}}=-\frac{\tau_{y}}{\rho_{\mathrm{sw}} f}=-\frac{\rho_{\mathrm{air}} C_{\mathrm{D}}|V| V_{\mathrm{y}}}{\rho_{\mathrm{sw}} f}
$$

where $\rho_{\text {air }}$ is the density of air $\left(1.22 \mathrm{~kg} \mathrm{~m}^{-3}\right.$ at $\left.15^{\circ} \mathrm{C}\right), C_{\mathrm{D}}$ is an empirical dimensionless drag coefficient $\left(C_{\mathrm{D}}=\right.$ $0.0014), f$ is the Coriolis parameter $\left[f=7.2710^{-5} \sin (\right.$ latitude)], $\rho_{\mathrm{sw}}$ is the density of seawater $\left(\sim 1025 \mathrm{~kg} \mathrm{~m}^{-3}\right)$, $|V|$ is the $6 \mathrm{~h}$ wind modulus and $V_{\mathrm{y}}$ is the wind component parallel to the coastline at each point along the coast (Table 1). Before estimating $I_{\mathrm{w}}$ the components of wind velocity were rotated clockwise into a new coordinate system with the $y$-axis aligned with the coastline (Table 1). The $I_{\mathrm{w}}$ estimates from Eq. (1) showing positive (negative) values of $I_{\mathrm{w}}$ at each point correspond to coastal upwelling (downwelling) conditions.

A least-squares method was used to fit both SST and $I_{\mathrm{w}}$ to 52 harmonics algorithms describing the annual cycle (Eq. 2) in order to get the deseasonalized time series ( ${ }^{\mathrm{dss}} S \mathrm{ST}$ and ${ }^{\mathrm{dss}} I_{\mathrm{w}}$, respectively). The choice of 52 harmonics was made in an attempt to include all the frequencies from monthly to weekly, but, actually, only the first 6 harmonics are significant.

$$
\operatorname{Var}=a_{0}+\sum_{i=1}^{52} b_{i} \sin (2 \pi i(t-\varphi) / 365.25)+{ }^{\mathrm{dss}} \operatorname{Var}
$$

where $t$ is time in days and $a_{0}, b_{i}$, and $\varphi$ are the fitting parameters. Var and dss Var stand for the original SST and $I_{\mathrm{w}}$ and for ${ }^{\text {dss }} S S T$ and ${ }^{d s s} I_{\mathrm{w}}$, respectively.

The long-term trends of SST $[\Gamma(\mathrm{SST})]$ and $I_{\mathrm{W}}\left[\Gamma\left(I_{\mathrm{w}}\right)\right]$ were analyzed from the linear fitting of ${ }^{\mathrm{dss}} \mathrm{SST}$ and ${ }^{\mathrm{dss}} I_{\mathrm{w}}$ versus time, respectively. The relationship between SST and $I_{\mathrm{w}}\left(\delta I_{\mathrm{w}} / \delta \mathrm{SST}\right)$ and ${ }^{\mathrm{dss}} \mathrm{SST}$ and ${ }^{\mathrm{dss}} I_{\mathrm{w}}\left(\delta^{\mathrm{dss}} I_{\mathrm{w}} /\right.$ $\delta^{\mathrm{dss}} \mathrm{SST}$ ) were evaluated by linear regression. In addition, we focused on the warmest period of the record, i.e. in the last 4 decades from 1970 until 2009 (hereafter, L4D). Some results were obtained on the basis of the mean monthly values of the $6 \mathrm{~h}\left({ }^{\mathrm{M} S S T},{ }^{\mathrm{M}} I_{\mathrm{w}}\right)$ and the deseasonalized ( ${ }^{\text {Mdss }} \mathrm{SST},{ }^{\mathrm{Mdss}} \mathrm{I}_{\mathrm{w}}$ ) time series for both variables. The use of the mean monthly values favours the comparison with climate indices that are only available on a monthly basis.

\section{RESULTS AND DISCUSSION}

\subsection{Seasonal cycles}

The mean seasonal variability in both SST and $I_{\mathrm{w}}$ (for $6 \mathrm{~h}$ and monthly mean time series) are summarized in Fig. 1 and Table 1. Fig. 1 shows the main characteristics of the seasonal cycle of SST $\left({ }^{\mathrm{sc} S S T}\right)$ and $I_{\mathrm{w}}\left({ }^{\mathrm{sc}} I_{\mathrm{w}}\right)$ in the selected grid nodes of the NCEP database for all EBUEs studied, giving the main features of the latitudi- 

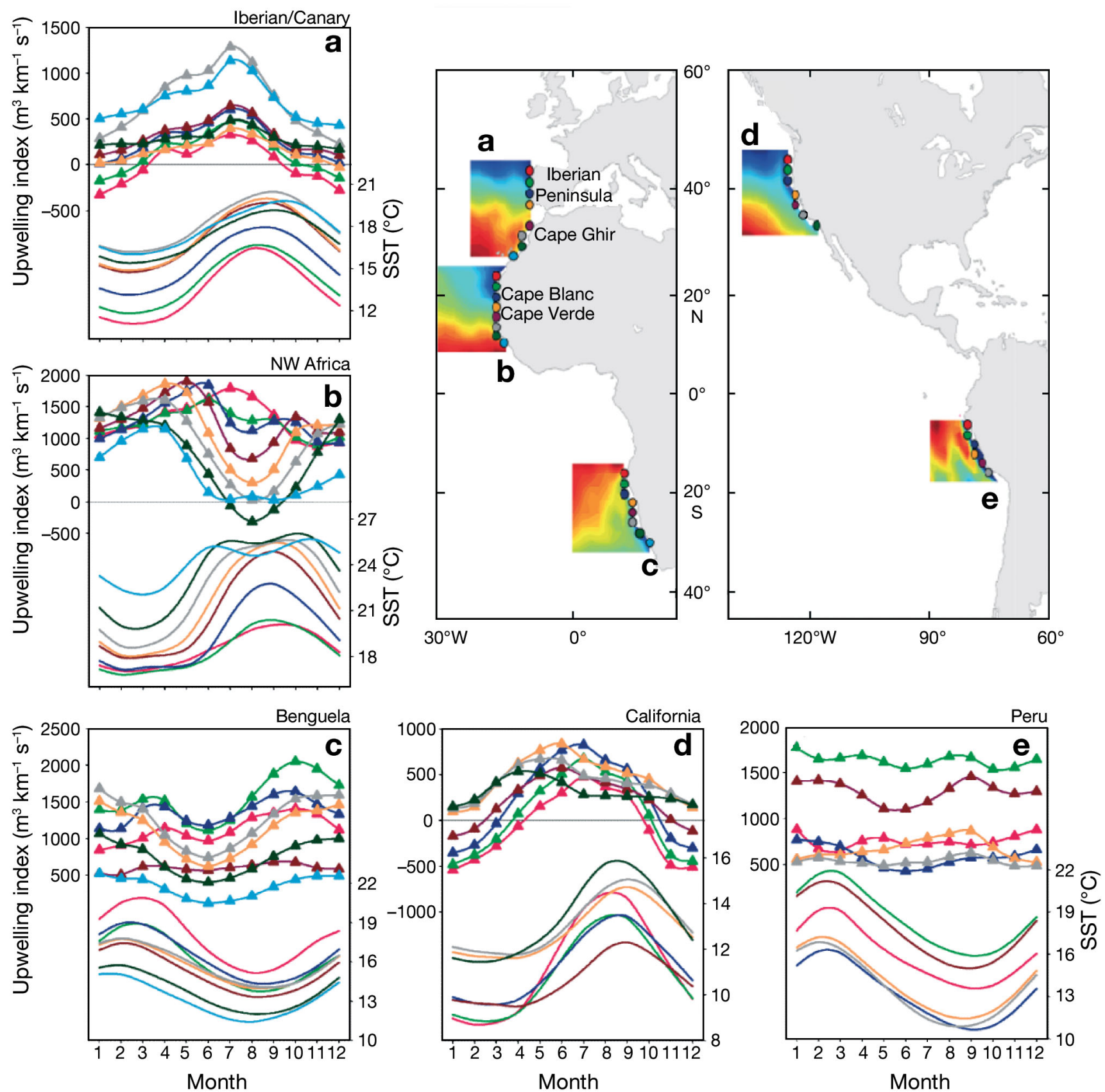

Fig. 1. Sea-surface temperature (SST) and upwelling index $\left(I_{\mathrm{w}}\right)$ variability for each of the regions defined in the study (a: Iberian/Canary; b: NW Africa; c: Benguela; d: California; e: Peru regions). The SST maps correspond to the mean values for the upwelling season of each region for the period 1974-1976, i.e. mean of the summer season (JJA) for the Iberian/Canary (a) and California (d) regions, mean of the spring (MAM) for the NW Africa region (b) and annual mean for Peru (e) and Benguela (c) regions. Each line plot shows the $61 \mathrm{yr}$ average seasonal SST and $I_{\mathrm{w}}$. Each line is keyed to the colour of the dot that indicates the geographical position (see also Table 1)

nal variability in both seasonal cycles. The difference in the temporal variability of both variables reflects the different 'inertia' between the atmosphere and ocean systems. The ${ }^{\mathrm{sc} S S T}$ explains between 65 and $95 \%$ of the $6 \mathrm{~h} \mathrm{SST} \mathrm{variance} \mathrm{in} \mathrm{all} \mathrm{regions} \mathrm{( \% var} \mathrm{SC} \mathrm{of} 6 \mathrm{~h} \mathrm{SST}$, Table 1). The variability in MSST is slightly (between 0.6 and $3 \%$ ) lower than that of the $6 \mathrm{~h} \mathrm{SST}$, showing that the high-frequency variability $(<1 \mathrm{mo})$ is very low. After removing the seasonal cycle, the remaining variability ( ${ }^{\mathrm{Mdss}} \mathrm{SST}$ ) is about $5-33 \%$ of ${ }^{\mathrm{M}} \mathrm{SST}$ ( $\%$ of ${ }^{\mathrm{M}} \mathrm{SST}$, Table 1). In contrast, ${ }^{\mathrm{sc}} I_{\mathrm{w}}$ explains a small portion (mean $\approx 15 \%$, reaching values as high as $42 \%$ in NW African region) of the total variability of $6 \mathrm{~h} I_{\mathrm{w}}$ (\%var $\mathrm{SC}$ of $6 \mathrm{~h} I_{\mathrm{w}}$, Table 1), and the variability in ${ }^{\mathrm{M}} I_{\mathrm{w}}$ is com- 


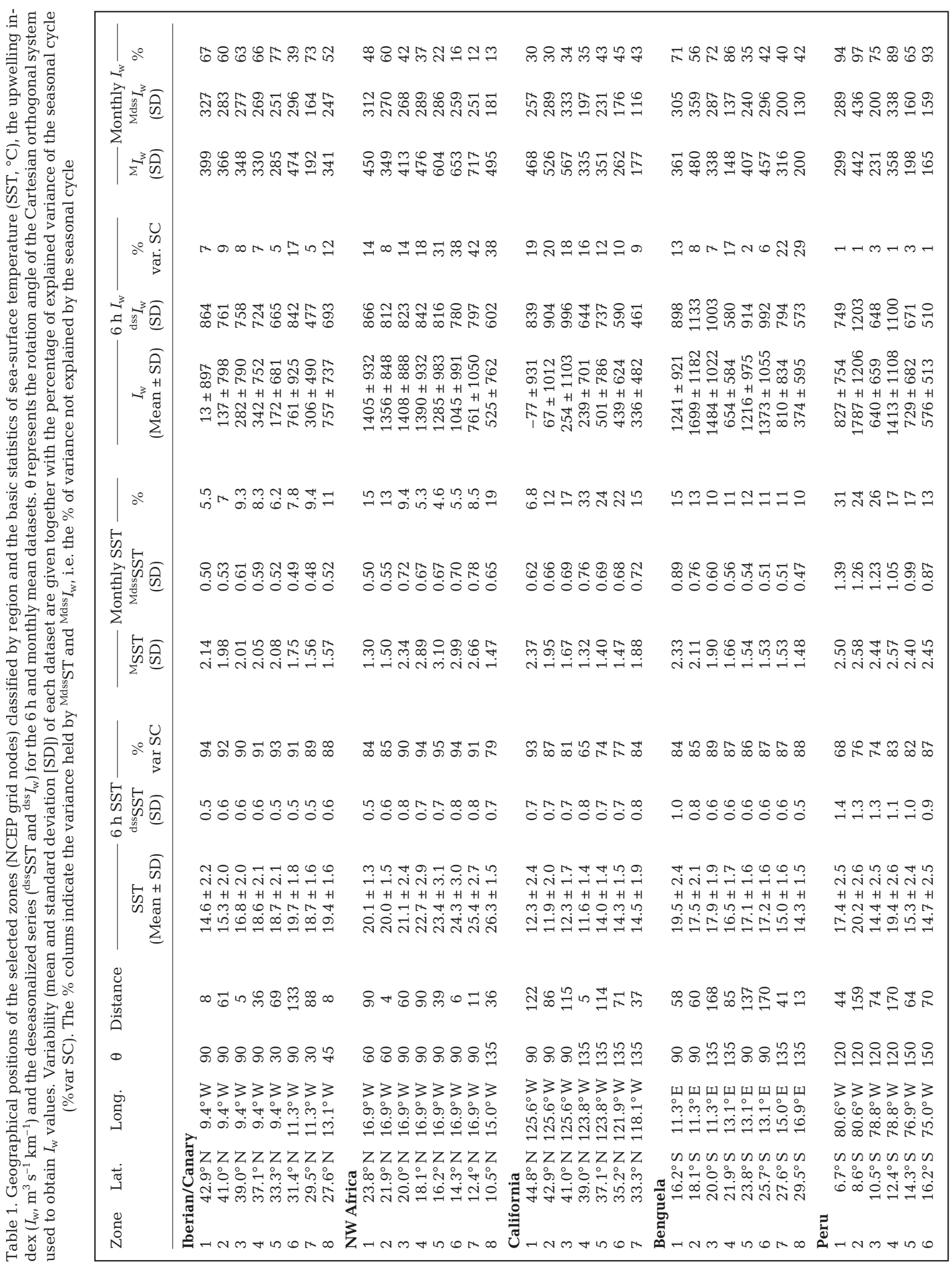


paratively much lower than that of the $6 \mathrm{~h} I_{\mathrm{w}}$ dataset. ${ }^{\mathrm{M}} I_{\mathrm{w}}$ removes between 53 and $93 \%$ of the total variance in $6 \mathrm{~h} I_{\mathrm{w}}$ (computed from the ratio of the squared std of ${ }^{\mathrm{M}} I_{\mathrm{w}}$ and SD of $I_{\mathrm{w}}$ ). After removing the seasonal cycle, ${ }^{\text {Mdss }} I_{\mathrm{W}}$ retains between 5 and $15 \%$ of the variability of $6 \mathrm{~h} I_{W}$ (ratio of the squared SD of ${ }^{M d s s} I_{\mathrm{W}}$ and SD of $I_{\mathrm{W}}$ ). This means that similar portions of both original datasets remain stable at long-term scales in spite of their different natures.

The Iberian/Canary region is characterized by large seasonal variability, with a positive trend southward in mean SST and $I_{\mathrm{w}}$ (Fig. 1). Both ${ }^{\mathrm{sc}} \mathrm{SST}$ and ${ }^{\mathrm{sc}} I_{\mathrm{w}}$ have nearly coincident maxima and minima, leading to a positive correlation between them (Fig. 1). The amplitude of ${ }^{\mathrm{sc} S S T}$ tends to decrease southward, whereas no clear trend is observed for ${ }^{\mathrm{sc}} I_{\mathrm{w}}$. The seasonal cycle (Table 1) explains a high portion of the variability in SST (88 to $94 \%$ ), but very little of that in $I_{\mathrm{W}}$ (5 to $17 \%$ ). The remaining variability in SST $\left({ }^{\mathrm{dss}} \mathrm{SST}\right.$ in $6 \mathrm{~h} \mathrm{SST}$, Table 1) is quite similar in all zones. The monthly averaged data give analogous results. Very low latitudinal variation is observed in ${ }^{\mathrm{dss}} \mathrm{SST}$, the percentage of variance retained at an interannual scale is between 5.5 and $11 \%$. ${ }^{\text {dss }} I_{\mathrm{w}}$ retains most of the variability in $I_{\mathrm{w},}$ not showing a clear latitudinal pattern, and the percentage range rises from 52 to $77 \%$ of ${ }^{\mathrm{M}} I_{\mathrm{w}}$. The ratio between the variance of ${ }^{\mathrm{M}} I_{\mathrm{w}}$ and the variance of $I_{\mathrm{w}}$ is $\sim 0.2$, which means that around $80 \%$ of the variability of $I_{\mathrm{w}}$ remains at scales of $<1 \mathrm{mo}$.

The NW African region shows strong seasonality (Wooster et al. 1976, Arístegui et al. 2009). The ${ }^{\mathrm{sc}} \mathrm{SST}$ is similar to that of the Iberian/Canary region, and the mean SST also increases southward (Fig. 1). The maximum amplitudes of ${ }^{\mathrm{sc}} \mathrm{SST}$ are located in the central zones of the region. The shape of the ${ }^{\mathrm{sc}} I_{\mathrm{w}}$ plot changes dramatically through the region, showing, in summer, high values in the north and low values towards the south (Fig. 1). As in the Iberian/Canary region, the variability retained by ${ }^{\mathrm{sc} S S T}$ (Table 1 ) is very high (79 to $95 \%$ ), and the variability found in the interannual scale range is slightly larger $\left(0.5^{\circ}\right.$ to $\left.0.8^{\circ} \mathrm{C}\right)$. ${ }^{\mathrm{sc}} I_{\mathrm{w}}$ retains an increasing percentage of variability towards the equator, reaching $42 \%$ at $12.4^{\circ} \mathrm{N}$. In fact, ${ }^{\mathrm{Mdss}} \mathrm{I}_{\mathrm{W}}$ retains the lowest percentage of variance $(12 \%)$ in the southern part of the region, whereas, in the northern part, these percentages are more similar to those of the Iberian/ Canary region.

The California region shows ${ }^{\mathrm{sc}} \mathrm{SST}$ and ${ }^{\mathrm{sc}} I_{\mathrm{w}}$ values quite similar to those of the Iberian/Canary region, with upwelling maxima occurring a bit earlier. The latitudinal variation of the mean SST and the amplitude in ${ }^{\mathrm{Sc} S S T}$ are lower than in the Iberian/Canary region (Fig. 1). The percentage of variance retained by ${ }^{\mathrm{sc} S S T}$ is also slightly lower (65 to $93 \%$ ), preserving the higher variability in ${ }^{\mathrm{dss}} \mathrm{SST}$, with no clear latitudinal variation
(Table 1). However, ${ }^{\mathrm{sc}} I_{\mathrm{W}}$ explains around twice the variability (9 to $20 \%$ ) found in the Iberian/Canary region, showing a decreasing trend in the ${ }^{\mathrm{dss}} I_{\mathrm{w}}$ variance towards the equator. The same behaviour is found in the monthly means, whereby the variance not retained by the monthly seasonal cycle ranges from 30 to $45 \%$, i.e. is about half that found in the Iberian/Canary region.

The Benguela and Peru regions have similar ${ }^{\mathrm{sc}} \mathrm{SST}$ values, showing symmetrical patterns to the ${ }^{\mathrm{sc}} \mathrm{SST}$ curves for the Iberian/Canary region (Fig. 1). Both explain much of the SST variability, and the ${ }^{\mathrm{sc}} \mathrm{SST}$ for the Peru region has a range $25 \%$ higher than those of other regions (Table 1 ). The ${ }^{\mathrm{sc}} I_{\mathrm{w}}$ values in both regions are very low. The percentage of variance retained in ${ }^{ }{ }^{\mathrm{Sc}} I_{\mathrm{W}}$ in the Peru region ranges between 1 and $3 \%$. For the Benguela region, the percentages are, in general, lower than those of the Iberian/Canary region except for 3 zones, which also show a clear seasonality in $I_{\mathrm{w}}$ (\%var SC > 15\%), 2 of them are located at the southern limit. The maximum $I_{\mathrm{w}}$ in the Benguela region occurs in austral spring, when SSTs are relatively low (Fig. 1). On the basis of ${ }^{\mathrm{M} S S T}$ and ${ }^{\mathrm{M}} \mathrm{I}_{\mathrm{w}}$, the variability in the Benguela region is quite similar to that in the Iberian/ Canary region, whereas the Peru region shows a very high interannual variability. The variability retained in the ${ }^{\mathrm{Mdss}} \mathrm{SST}$ and ${ }^{\mathrm{Mdss}} \mathrm{I}_{\mathrm{w}}$ of the Benguela region (0.47 to $0.89^{\circ} \mathrm{C}$ and 130 to $359 \mathrm{~m}^{3} \mathrm{~s}^{-1} \mathrm{~km}^{-1}$, respectively; Table 1) are of the same order as those of the Iberian/Canary region, but a positive trend is recorded towards the equator. In the Peru region, the percentages of variance in ${ }^{\text {Mdss }}$ SST and ${ }^{\text {Mdss }} I_{\mathrm{w}}$ (13 to $31 \%$ and 65 to $97 \%$, respectively) are noticeably higher than those of the other EBUEs, suggesting that long-term dynamic processes affect both variables dramatically (Mendelssohn \& Schwing 2002).

\subsection{Interannual variability}

Table A1 in the Appendix shows the long-term variations in SST and $I_{\mathrm{w}}\left[\Gamma(\mathrm{SST})\right.$ and $\Gamma\left(I_{\mathrm{w}}\right)$, respectively], the correlation between the deseasonalized series $\left(\delta^{\text {dss }} I_{\mathrm{w}} /\right.$ $\delta^{\text {dss }} \mathrm{SST}$ ) and the corresponding $\mathrm{p}$-values. In addition to the original dataset, the statistical results for the longterm variability in the $\mathrm{L} 4 \mathrm{D}$ are also given.

The $I_{\mathrm{w}}$ estimations using the NCEP outcomes from 1948 to 2009 show a long-term decrease in upwelling intensity in the Iberian/Canary region (Table A1). $I_{\mathrm{w}}$ values show statistical significance everywhere except in the central zones of the region ( $p>0.05)$. A general weakening of $I_{\mathrm{w}}$ is observed throughout the region in the $\Gamma\left(I_{\mathrm{w}}\right)$ values. The maximum $I_{\mathrm{w}}$ weakening $(-28 \pm$ $2 \mathrm{~m}^{3} \mathrm{~s}^{-1} \mathrm{~km}^{-1}$ decade $^{-1}$ ) is located at $31.4^{\circ} \mathrm{N}$, and the minimum $\left(-8 \pm 1 \mathrm{~m}^{3} \mathrm{~s}^{-1} \mathrm{~km}^{-1} \mathrm{decade}^{-1}\right)$ is at $39.0^{\circ} \mathrm{N}$. In general, the observed trends in ${ }^{\mathrm{dss}} I_{\mathrm{w}}$ for the whole 
period are intensified for all zones when only the analysis of the L4D period is considered. As a result, the $\Gamma\left(I_{\mathrm{w}}\right)$ values for some zones are contrary to the upwelling decrease observed for the whole period, showing a significant intensification of upwelling (see the 2 southernmost latitudes, Table A1). These analyses agree with the earlier study of Lemos \& Sansó (2006), who also detected this interannual weakening of $I_{\mathrm{w}}$ for the region between the latitudes of 36 and $44^{\circ} \mathrm{N}$ and for the period 1970-2000. The minimum value of $\Gamma\left(I_{\mathrm{w}}\right)$ for the L4D period $\left(-37 \pm 3 \mathrm{~m}^{3} \mathrm{~s}^{-1} \mathrm{~km}^{-1}\right.$ decade $\left.^{-1}\right)$ is located at $42.9^{\circ} \mathrm{N}$. This value is similar to the long-term $I_{\mathrm{w}}$ decrease reported by Pérez et al. (2010), who found a value of $-44 \pm 14 \mathrm{~m}^{3} \mathrm{~s}^{-1} \mathrm{~km}^{-1}$ decade $^{-1}$ for the trend from 1965 to 2007 at $43^{\circ} \mathrm{N}, 11^{\circ} \mathrm{W}$ (off the Galician coast) and using $6 \mathrm{~h}$ sea-level pressure maps. The upwelling reduction northwest of the Iberian Peninsula was associated with a relaxation of the zonal atmospheric pressure gradient in the Bay of Biscay (Fig. 1 in Pérez et al. 2010). This relaxation at interannual scales would explain the northward decrease of the coastal upwelling intensity in the Iberian/Canary region found for the L4D period.

In parallel to the weakening of coastal upwelling, every zone in the Iberian/Canary region shows a statistically significant warming trend at an interannual scale. As was observed for the $I_{W}$ decrease, an intensification of $\Gamma(\mathrm{SST})$ is greater for the L4D period than the value computed for the whole period (Table A1). Lemos \& Sansó (2006) also found a similar change in SSTs, reporting a warming trend in coastal waters from the early 1970 s to 2000 , in contrast to the cooling trend from 1940 to the early 1970s. Maximum warming was found in the central zones of this region, at $39.0^{\circ} \mathrm{N}$ and at $37.1^{\circ} \mathrm{N}$ for the whole period and at $37.1^{\circ} \mathrm{N}$ for the L4D period, where $\Gamma(\mathrm{SST})$ is $0.135 \pm 0.001,0.134 \pm$ 0.001 and $0.359 \pm 0.002^{\circ} \mathrm{C}$ decade $^{-1}$, respectively. The $\Gamma(\mathrm{SST})$ values along this region are generally lower than the observed rates of $0.3^{\circ}$ to $0.46^{\circ} \mathrm{C}$ decade $^{-1}$ found by Gómez-Gesteira et al. (2008b) on the Iberian coast using advanced very high resolution radiometer for the period 1985-2005.

The interannual variability in $I_{\mathrm{W}}$ and SST confirm the decrease of the upwelling intensity under a warming scenario in most of the northern regions of the Canary Current System during the last 60 yr (Lemos \& Pires 2004, Lemos \& Sansó 2006, Pérez et al. 2010). Nevertheless, the statistically significant exceptions to this general trend that reached an upwelling intensification of $16 \pm 3 \mathrm{~m}^{3} \mathrm{~s}^{-1} \mathrm{~km}^{-1}$ decade $^{-1}\left(27.6^{\circ} \mathrm{N}\right.$; Table A1) are found south of Cape Ghir $\left(\sim 31^{\circ} \mathrm{N}\right)$. In contrast to these results, Bakun (1990) found $I_{\mathrm{w}}$ values strengthening at these latitudes, deduced from the along-shore geostrophic wind, as did McGregor et al. (2007), but from alkenone SST reconstructions.
The linear relationship between $I_{\mathrm{w}}$ and SST $\left(\delta I_{\mathrm{w}} /\right.$ $\delta \mathrm{SST}$, not shown) values throughout the Iberian/ Canary region show positive values, ranging from $24 \pm 1$ to $66 \pm 2 \mathrm{~m}^{3} \mathrm{~s}^{-1} \mathrm{~km}^{-1}{ }^{\circ} \mathrm{C}^{-1}$. These positive values are probably due to a coinciding period of prevailing upwelling-favourable winds between April and September and the warmest season (Fig. 1). On the other hand, the $\delta^{\mathrm{dss}} I_{\mathrm{w}} / \delta^{\mathrm{dss}} \mathrm{SST}$ ratios are negative throughout the whole region, with very similar values, with the most and least negative ratios located at $31.4^{\circ} \mathrm{N}$ and $29.5^{\circ} \mathrm{N}$, respectively (Table A1). When these ratios are computed from ${ }^{\text {Mdss }}$ SST and ${ }^{\text {Mdss }} I_{\mathrm{W}}$, the results obtained are very similar, which supports the conclusion that interannual dynamic processes exist behind this pattern. The highest and lowest values of $\delta^{\mathrm{dss}} I_{\mathrm{w}} / \delta^{\mathrm{dss}} S S T$ found in the vicinity of Cape Ghir could be a cause of the quasi-persistent filament that characterizes this zone (Hagen et al. 1996, Barton 1998).

The analyses of SST and $I_{\mathrm{w}}$ were extended throughout the NW African region (Fig. 1), in order to investigate latitudinal variability. The $\Gamma(\mathrm{SST})$ values during the whole period retain the warming trend previously observed in the Iberian/Canary region without exception (Table A1). The $\Gamma(\mathrm{SST})$ is characterized by a slightly southward increase that ranged between a minimum of $0.021 \pm 0.001^{\circ} \mathrm{C}$ decade $^{-1}$ at $23.8^{\circ} \mathrm{N}$ and a maximum in interannual warming of $0.176 \pm 0.001^{\circ} \mathrm{C}$ decade $^{-1}$ at $12.4^{\circ} \mathrm{N}$. The $\Gamma(\mathrm{SST})$ for the L4D period shows stronger warming rates than for the whole period, ranging from 0.16 to $0.36^{\circ} \mathrm{C}$ decade $^{-1}$. The most intense warming trend, with a value of $0.362 \pm 0.003^{\circ} \mathrm{C}$ decade $^{-1}$, was observed at $20^{\circ} \mathrm{N}$, where the correlation coefficient also reached a maximum value $(r=0.46)$. In general terms, a warming trend in the NW African region was also found in parallel to the weakening of coastal upwelling, with only 1 exception for the whole period: $\Gamma\left(I_{\mathrm{w}}\right)=11 \pm 2 \mathrm{~m}^{3}$ $\mathrm{s}^{-1} \mathrm{~km}^{-1}$ decade $^{-1}$ at $23.8^{\circ} \mathrm{N}$. As a potential response to this upwelling intensification, Gregg et al. (2005) found the only chlorophyll $a$ increase at this latitudinal range in the NW African Upwelling System. In contrast, the intensified weakening of $I_{\mathrm{w}}$ for both the whole and L4D periods are located in the central regions, in front of the embayment between Cape Blanc $\left(\sim 20.1^{\circ} \mathrm{N}\right)$ and Cape Verde $\left(\sim 16.0^{\circ} \mathrm{N}\right)$, with minimum $\Gamma\left(I_{\mathrm{w}}\right)$ values at $18.1^{\circ} \mathrm{N}$ of $-64 \pm 2$ and $-62 \pm 3 \mathrm{~m}^{3} \mathrm{~s}^{-1} \mathrm{~km}^{-1}$ decade $^{-1}$ for the whole and L4D periods, respectively.

The $\delta I_{\mathrm{w}} / \delta \mathrm{SST}$ (not shown) showed negative values (from $-43 \pm 2$ to $-266 \pm 1 \mathrm{~m}^{3} \mathrm{~s}^{-1} \mathrm{~km}^{-1}{ }^{\circ} \mathrm{C}^{-1}$ ) throughout all of the NW African region; this corresponds with the fact that the warm season is the less favourable upwelling season (Fig. 1). The values of $\delta^{\mathrm{dss}} I_{\mathrm{w}} / \delta^{\mathrm{dss}} \mathrm{SST}$ for the whole-period dataset are also negative throughout the region, with no clear spatial distribution (Table A1). The values of $\delta^{\text {dss }} I_{\mathrm{w}} / \delta^{\text {dss }} S S T$ using the L4D-period dataset are also negative and very similar to the former. 
The results obtained in the Iberian/Canary region can be compared with those of the California region (33.3 ${ }^{\circ}$ to $44.8^{\circ} \mathrm{N}$; Fig. 1) in order to determine how specific the characteristics are. The study of $\Gamma\left(I_{\mathrm{w}}\right)$ in the California region for the whole period (Table A1) shows statistically significant values primarily in the southern zones, where the intensification of upwelling is indicated. This is in contrast to the significant weakening of coastal upwelling found in the Iberian/ Canary region. The estimations of $\Gamma\left(I_{\mathrm{w}}\right)$ for the L4D period are significant, mainly in the southern zones, and show different trends. The intensification of $I_{\mathrm{w}}$ persists only at $35.2^{\circ} \mathrm{N}$, with values of $18 \pm 1$ and $12 \pm$ $2 \mathrm{~m}^{3} \mathrm{~km}^{-1} \mathrm{~s}^{-1}$ decade ${ }^{-1}$ in both the whole and L4D periods. $\Gamma(\mathrm{SST})$ values also show a slight, regular cooling in the northern and central zones, with a slight warming towards the south for the whole period, in comparison to the estimated general warming in the Iberian/Canary region. This cooling reached a value of $-0.10^{\circ} \mathrm{C}$ decade ${ }^{-1}$ at $39^{\circ} \mathrm{N}$, with a notable regression coefficient of 0.23 . The $\Gamma(\mathrm{SST})$ estimated for the L4D period also repeated the low-value trends, with no clear latitudinal pattern. In this sense, it is notable that the observed SST warming at $35.2^{\circ} \mathrm{N}$ (cooling at $39.0^{\circ} \mathrm{N}$ ) coincides with a significant $I_{\mathrm{w}}$ enhancement (weakening) following Bakun's scheme and in contrast to what can be seen in the Iberian/Canary region. Schwing \& Mendelssohn (1997), Schwing et al. (1998) and Mendelssohn \& Schwing (2002), using state-space models, observed a reinforcement of coastal upwelling together with a long-term warming trend in some locations $\left(32^{\circ}\right.$ to $\left.40^{\circ} \mathrm{N}\right)$. Snyder et al. (2003) corroborated these earlier results, using a regional climate model, despite the lack of a coupled dynamic ocean model to quantify impacts over a range of oceanographic processes. In any case, the regional and overall analyses of the California region (Bakun 1990, Chavez \& Messié 2009) indicated a reinforcement of coastal upwelling, while the NCEP dataset used here indicated a predominantly weak cooling and no clear $I_{\mathrm{w}}$ trend.

$\delta I_{\mathrm{w}} / \delta \mathrm{SST}$ (not shown) in the California region repeat the southward decrease, showing clear seasonal $I_{\mathrm{w}}$ changes in relation to latitude (Fig. 1), as was observed in the Iberian/Canary region. The $\delta I_{\mathrm{w}} / \delta \mathrm{SST}$ values vary from highly positive $\left(>100 \mathrm{~m}^{3} \mathrm{~km}^{-1} \mathrm{~s}^{-1}{ }^{\circ} \mathrm{C}^{-1}\right)$ in the north to low or even negative, coincident with a parallel change in the correlation coefficients (not shown). The $\delta^{\mathrm{dss}} I_{\mathrm{w}} / \delta^{\mathrm{dss}} \mathrm{SST}$ estimations show quite homogeneous negative values, ranging from $-40 \pm 3$ to $-103 \pm$ $5 \mathrm{~m}^{3} \mathrm{~km}^{-1} \mathrm{~s}^{-1}{ }^{\circ} \mathrm{C}^{-1}$ and similar to the ones found in the Iberian/Canary region (Table A1). The values of the ratio for the L4D period dataset in the California region are very similar to those obtained for the whole-period dataset.
In relation to the Benguela region, the significant $\Gamma\left(I_{\mathrm{w}}\right)$ for the whole period shows an intensification of upwelling in the central zones of the region together with a weakening towards the equator (Table A1). Importantly, for the L4D period, a general enhancement of upwelling intensity is found, ranging from $28 \pm 3$ to $100 \pm 4 \mathrm{~m}^{3} \mathrm{~km}^{-1} \mathrm{~s}^{-1}$ decade ${ }^{-1}$ and with correlation coefficients higher than for the whole period. These observations were found coincident with a general warming $[\Gamma(\mathrm{SST})>0]$ for both the whole and L4D periods (except for the zone at $21.9^{\circ} \mathrm{S}$ in the whole period). Similar to what was observed in the Iberian/Canary region, warming in the Benguela region has been more intense in the last few decades, reaching a maximum value of $0.237 \pm 0.004^{\circ} \mathrm{C}$ decade $^{-1}$ at $16.2^{\circ} \mathrm{S}$. The $\delta I_{\mathrm{w}} / \delta \mathrm{SST}$ values (not shown) are clearly separated into 2 groups, one with negative values in the northern half of the region and another group with positive values in the southern half. This fact is due to the different regimes of ${ }^{\mathrm{sc}} I_{\mathrm{w}}$, which, for the northern zones, has higher values of $I_{\mathrm{w}}$ prior to the warm season and, for the southern zones,

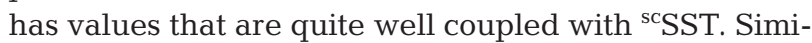
larly, the $\delta^{\mathrm{dss}} I_{\mathrm{w}} / \delta^{\mathrm{dss}} \mathrm{SST}$ distribution for the whole period also separated this region into 2 parts, with positive values northward of $23.8^{\circ} \mathrm{S}$ and negative ratios southwards, except for 2 zones with non-significant values (Table A1). The $\delta^{\mathrm{dss}} I_{\mathrm{w}} / \delta^{\mathrm{dss}} \mathrm{SST}$ values are also positive for the L4D period north of $23.8^{\circ} \mathrm{N}$, with non-significant values south of this latitude. Besides this difference between north and south in the Benguela region, the general results obtained here seem to agree with Bakun's scheme of the enhancement of upwelling under a longterm warming scenario.

In the Peru region, $\Gamma\left(I_{\mathrm{w}}\right)$ primarily suggests a weakening of upwelling for both the whole and L4D periods. For the L4D period, a unique exception is the relatively important reinforcement of upwelling at the south limit. However, the $\Gamma(\mathrm{SST})$ values computed for both periods show some differences, a general warming for the whole period and a general cooling for the L4D period north of $12.4^{\circ} \mathrm{S}$, except in the 2 southern zones, which could be related to processes of interdecadal variability (Mendelssohn \& Schwing 2002, Chavez \& Messié 2009). The $\delta I_{\mathrm{w}} / \delta S S T$ values (not shown) are positive, except in the 2 southern zones, indicating a probable seasonal decoupling between ${ }^{\mathrm{sc}} I_{\mathrm{w}}$ and ${ }^{\mathrm{sc} S S T}$. The $\delta^{\text {dss }} I_{\mathrm{w}} / \delta^{\text {dss }} \mathrm{SST}$ values are also positive, ranging from 20 to $103 \mathrm{~m}^{3} \mathrm{~km}^{-1} \mathrm{~s}^{-1}{ }^{\circ} \mathrm{C}^{-1}$ for the whole period and from 37 to $136 \mathrm{~m}^{3} \mathrm{~km}^{-1} \mathrm{~s}^{-1}{ }^{\circ} \mathrm{C}^{-1}$ for the L4D period, contrasting what is found in the Iberian/Canary and NW African regions. Furthermore, the general trends observed in $I_{\mathrm{w}}$ and SST for the Peru region are different from the other EBUEs, showing different trends depending on the period of time studied. For the whole period, the warming trend and a general weakening of 
upwelling resemble the results obtained for the Iberian/Canary and NW African regions. Nevertheless, for the L4D period, the cooling north of $12.4^{\circ} \mathrm{S}$, coincident with a weakening trend in the winds favourable to upwelling, does not reflect Bakun's scheme and is not coincident with any other results.

Up to this point, the results obtained in this analysis show important warming trends in the Iberian/Canary region accompanied by a considerable weakening of upwelling. Both trends are similarly found, but to a greater degree, in the NW African region. For the California region, the slight cooling does not correlate with any clear trend in the intensity of the winds favourable to upwelling. In the southern hemisphere some similarities with respect to the Iberian/Canary region can be found in the results for the Peru region, but with weak trends and only for the whole period. In the Benguela region, the general warming trend coincides with an enhancement in upwelling and not with the weakening found in the Iberian/Canary region. Belkin (2009) found warming trends for the period between 1982 and 2006 in the Iberian Coastal, Canary Current and Benguela Current Upwelling Systems and a slight cooling trend in the California and Humboldt Current Upwelling Systems. The trends obtained here for the L4D period are in agreement with Belkin's findings, except for the California region, where the cooling trend is only found for the whole period (1949-2009). Similarly, Chavez et al. (2010) also found a cooling trend in the Peru and North California Upwelling Systems and a warming trend in the East Atlantic Upwelling System for the period 1981-2009. Nevertheless, they found general warming in all the EBUEs when considering the very long period of 1910-2009.

With respect to the ratio between variables $\left(\delta^{\mathrm{dss}} I_{\mathrm{w}} /\right.$ $\delta^{\text {dss }} \mathrm{SST}$ ) some insight can be gained from the results. From a study focused on the Canary Current Upwelling Ecosystem $\left(7^{\circ}\right.$ to $\left.44^{\circ} \mathrm{N}\right)$, Wooster et al. (1976) found that the SST horizontal gradients (between coast and ocean) and the seasonal variability in $I_{\mathrm{w}}$ were strongly related, the surface winds being the major driving force in coastal processes. These authors obtained values of $\delta^{\text {dss }} I_{\mathrm{w}} / \delta^{\mathrm{dss}} \mathrm{SST}$ from $-100 \mathrm{~m}^{3} \mathrm{~km}^{-1} \mathrm{~s}^{-1}{ }^{\circ} \mathrm{C}^{-1}$ at the northern limit to $-200 \mathrm{~m}^{3} \mathrm{~km}^{-1} \mathrm{~s}^{-1}{ }^{\circ} \mathrm{C}^{-1}$ at Cape Blanc. In the present study, negative values were found $\left(-80 \pm 30 \mathrm{~m}^{3}\right.$ $\mathrm{km}^{-1} \mathrm{~s}^{-1}{ }^{\circ} \mathrm{C}^{-1}$ ) for the Iberian/Canary region, but less negative than those obtained from the anomalies described by Wooster et al. (1976), and the same conclusions can be drawn for the NW African region. These results indicate that coastal upwelling is not the main physical process to follow the interannual SST variability. Even though a decrease in the frequency of upwelling events can be deduced, other long-term processes related to the changes in atmospheric and oceanic large-scale circulation should be taken into ac- count in order to understand the results described above. Belkin (2009) also pointed out a relation between the North Atlantic Oscillation Index and the variability in warming trends in the North Atlantic. Furthermore, Bakun's scheme is proposed primarily for upwelling-favourable seasons, and large-scale circulation patterns, related to the variability in climate indices, have no linear effects (Mathieu et al. 2004). From these facts, it is very likely that these long-term changes can produce alterations in ${ }^{\mathrm{sc}} \mathrm{SST}$ and ${ }^{\mathrm{sc}} I_{\mathrm{w}}$ and so the observed long-term trend would be seasonally different. A statistical analysis of the seasonal variability in $\Gamma(\mathrm{SST})$ and $\Gamma\left(I_{\mathrm{w}}\right)$ and their covariation with a selection of the most relevant climatic indices could be of great help in revealing some clues on the forcing underlying the interannual variability in $I_{\mathrm{w}}$.

\subsection{Seasonal relations among $I_{\mathrm{w}}, \mathrm{SST}$ and climate indices}

The interannual variability in ${ }^{\text {Mdss }} I_{\mathrm{W}}$ and ${ }^{\text {Mdss }} \mathrm{SST}$ do not follow a homogenous distribution, either throughout the Iberian/Canary and NW African regions or throughout the seasons (Fig. 2). The latitudinal variability in ${ }^{M d s s} I_{W}$ (not shown) is nearly constant throughout the seasons in the Iberian/Canary region, with a minimum standard deviation of $\sim 200 \mathrm{~m}^{3} \mathrm{~km}^{-1} \mathrm{~s}^{-1}$ in autumn and a maximum of $\sim 350 \mathrm{~m}^{3} \mathrm{~km}^{-1} \mathrm{~s}^{-1}$ in winter and spring. The range of values is almost the same for the NW African region (not shown), with the minimum and maximum values located in the same seasons, but the variability in ${ }^{\text {Mdss }} I_{\mathrm{W}}$ is not as constant with latitude as for the Iberian/ Canary regions. ${ }^{\text {Mdss }}$ SST shows more spatial variability in both regions (Fig. 2a). In the Iberian/Canary region, the maximum is found in autumn and winter, with a value around $\sim 0.67^{\circ} \mathrm{C}$ for both seasons, and is located at $37.1^{\circ}$ and $39^{\circ} \mathrm{N}$, respectively. In the rest of the regions, all seasons show similar variability, but, in general, minimum variability occurs in spring, with a standard deviation range of $0.45^{\circ}$ to $0.52^{\circ} \mathrm{C}$. In the NW African region (Fig. 2a), maximum variability in ${ }^{\mathrm{Mdss}} \mathrm{SST}$ is found in spring $\left(\sim 1^{\circ} \mathrm{C}\right)$ and summer $\left(\sim 0.8^{\circ} \mathrm{C}\right)$ in the south (at $12.4^{\circ} \mathrm{N}$ ). North of the NW African region, the variability is very similar in all seasons, showing minimum values in summer. South of $16.2^{\circ} \mathrm{N}$, variability is quite different between seasons, with minimum values in autumn $\left(\sim 0.4^{\circ} \mathrm{C}\right)$. The warming trends in the Iberian/Canary region are strong $\left(0.1^{\circ}\right.$ to $0.2^{\circ} \mathrm{C}$ decade $^{-1}$; Fig. 2c), showing a high percentage ( 10 to $22 \%$; Fig. $2 \mathrm{~b}$ ) of explained variance of $\Gamma(\mathrm{SST})$ in autumn and winter in the central zones of the region. In summer and spring, the trends and percentages of explained variance are systematically lower. These trends are low at the limits of the region, with lower percentages of explained vari- 

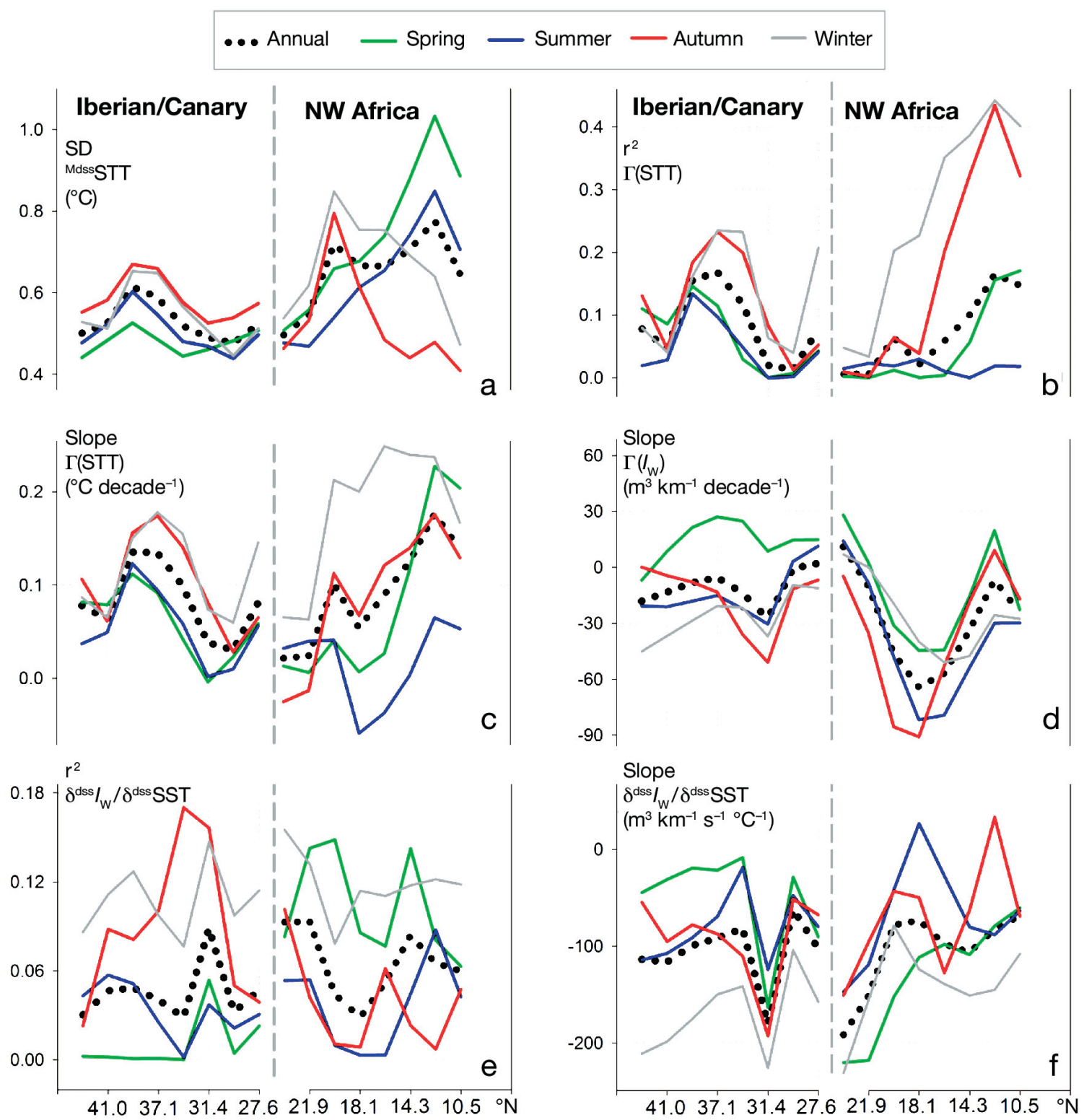

\section{California}
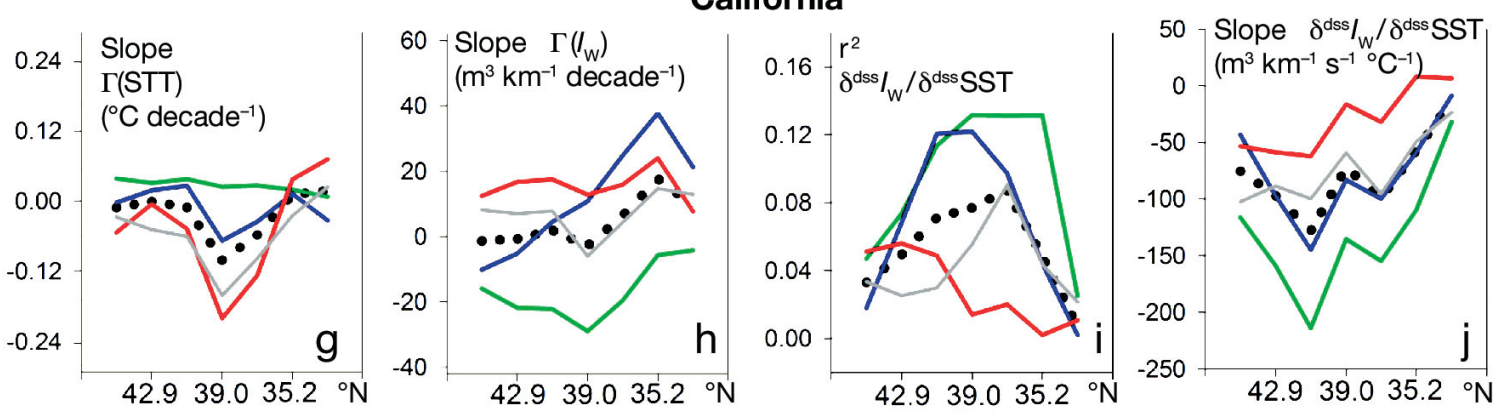

Fig. 2. ${ }^{\mathrm{Mdss}} \mathrm{SST}$ and ${ }^{\mathrm{Mdss}} I_{\mathrm{W}}$ variability and statistics in the Iberian/Canary and NW Africa regions for the whole period (1948-2009). (a) Standard deviation (SD) of Mdss SST, (b) determination coefficient for the long-term trend in ${ }^{d s s}$ SST $[\Gamma(\mathrm{SST})]$ (c,d) long-term trends $\left[\Gamma(\mathrm{SST}), \Gamma\left(I_{\mathrm{w}}\right)\right]$ and $(\mathrm{e}, \mathrm{f})$ correlations between variables $\left(\delta^{\mathrm{dss}} I_{\mathrm{w}} / \delta^{\mathrm{dss}} \mathrm{SST}\right)$. The annual mean is also shown (black dotted line), together with those of the spring (green line), summer (blue line), autumn (red line) and winter (grey line) seasons. Trends ( $g$,h) and correlations between each other variable $(i, j)$ are also shown for the California region 
ance (Fig. 2b). The warming is intensified when using the L4D dataset (not shown), with values ranging from $0.15^{\circ}$ to $0.4^{\circ} \mathrm{C}$ decade $^{-1}$. In addition, the difference in the values of $\Gamma$ (SST) between seasons diminishes (Fig. 2c). An almost constant warming $\left(\sim 0.2^{\circ} \mathrm{C}_{\text {decade }^{-1}}\right.$; Fig $\left.2 \mathrm{c}\right)$ is found in the winter, south of $20^{\circ} \mathrm{N}$ (NW Africa), with high percentages of explained variance (Fig. 2b). This pattern is very similar in autumn, but with lower trends than in winter. Between 23.8 and $20^{\circ} \mathrm{N}$ and in summer throughout the region, the warming is not as clear. In spring, the warming trend increases its values south of $14.3^{\circ} \mathrm{N}$, achieving winter values at $12.4^{\circ} \mathrm{N} . \Gamma\left(I_{\mathrm{w}}\right)$ in the Iberian/Canary region shows clear negative values all year round, except in spring (Fig. 2d). A weakening of the upwelling intensity achieves a strong minimum value of $-50 \mathrm{~m}^{3} \mathrm{~km}^{-1} \mathrm{~s}^{-1}$ decade $^{-1}$ in winter near Cape Ghir $\left(31.4^{\circ} \mathrm{N}\right)$. In spring, a slight systematic reinforcement of the upwelling intensity for the whole period could suggest a possible explanation to the contradictory observations given by McGregor et al. (2007) using alkenone as a proxy for SST. Nevertheless, the reinforcement disappears when analyzing the L4D period (not shown). In the central zones of the NW African region $\left(20^{\circ}\right.$ to $\left.16.2^{\circ} \mathrm{N}\right)$, the weakening is very important, with a minimum value of ca. $-80 \mathrm{~m}^{3} \mathrm{~km}^{-1} \mathrm{~s}^{-1}$ decade $^{-1}$ at $18.1^{\circ} \mathrm{N}$ in winter and a high percentage of explained variance for all seasons (Fig. 2d). North of $20^{\circ} \mathrm{N}$, trends can be estimated with confidence, but not so south of $16.2^{\circ} \mathrm{N}$. Comparing these results with those obtained for the other EBUE in the northern hemisphere, that is, for the California region, the opposite trends are observed. In the California region, a cooling trend in the central zones of the region $\left(39\right.$ and $37.1^{\circ} \mathrm{N}$ ) is found in autumn and winter, with a high percentage of explained variance and values around $-0.2^{\circ} \mathrm{C}_{\text {decade }}{ }^{-1}$ (Fig. $2 \mathrm{~g}$ ). The reinforcement of upwelling-favourable winds is noticeable in the south of the region $\left(35.2\right.$ and $\left.33.3^{\circ} \mathrm{N}\right)$ in autumn and summer, with a maximum of $\sim 40 \mathrm{~m}^{3}$ $\mathrm{km}^{-1} \mathrm{~s}^{-1}$ decade $^{-1}$ in summer at $35.2^{\circ} \mathrm{N}$ (Fig. $2 \mathrm{~h}$ ). The weakening observed in spring throughout the region shows low values in the percentage of explained variance at $39^{\circ} \mathrm{N}$.

High correlations of $\delta^{\mathrm{dss}} I_{\mathrm{w}} / \delta^{\mathrm{dss}} \mathrm{SST}$ in the Iberian/ Canary region are obtained in winter and autumn over almost the whole region (Fig. 2e,f). $\delta^{\mathrm{dss}} I_{\mathrm{w}} / \delta^{\mathrm{dss}} \mathrm{SST}$ values are negative throughout the region, and the zone proximate to Cape Ghir $\left(31.4^{\circ} \mathrm{N}\right)$ is where the sharpest slopes are found (Fig. 2e). In this zone, the minimum value of $\delta^{\text {dss }} I_{W} / \delta^{\text {dss }}$ SST is achieved (ca. $-225 \mathrm{~m}^{3} \mathrm{~km}^{-1} \mathrm{~s}^{-1}$ ${ }^{\circ} \mathrm{C}^{-1}$ ) in spring, though values are very similar for all seasons compared to those found in the rest of the region. In the NW African region, $\delta^{\text {dss }} I_{\mathrm{w}} / \delta^{\text {dss }} \mathrm{SST}$ is highly correlated in winter and spring, with a minimum value in the northern zones $\left(23.8\right.$ and $\left.21.9^{\circ} \mathrm{N}\right)$ in spring, similar to that found in the Iberian/Canary region (Fig. 2e,f).
These negative values at $31.4^{\circ} \mathrm{N}$ in the Iberian/Canary region and north of the NW African region are very similar to the anomalies found by Wooster et al. (1976), suggesting an important modulation of $I_{\mathrm{w}}$ over SST. The values obtained for $\delta^{\mathrm{dss}} I_{\mathrm{w}} / \delta^{\mathrm{dss}} \mathrm{SST}$ in the California region have high correlations, mostly in spring and summer throughout the region and especially in the central zones $\left(41^{\circ}\right.$ to $\left.35.2^{\circ} \mathrm{N}\right)$, which correspond to negative values (Fig. 2i,j). The minimum value found in spring at $41^{\circ} \mathrm{N}$ (ca. $-225 \mathrm{~m}^{3} \mathrm{~km}^{-1} \mathrm{~s}^{-1}{ }^{\circ} \mathrm{C}^{-1}$; Fig. $2 \mathrm{j}$ ) is also of the order of those found by Wooster et al. (1976), suggesting the importance of upwelling processes in spring. In summer, well-correlated negative values are obtained between 39 and $35.2^{\circ} \mathrm{N}$ and in autumn in the north of the region.

The variability in ${ }^{\text {Mdss }} S S T$ and ${ }^{\text {Mdss }} I_{\mathrm{w}}$ can be related to some extent to the variability in climatic modes. Several climate indices were investigated, and the correlation with these variables for the Iberian/Canary and NW African regions provided interesting results (Fig. 3). The Atlantic Multidecadal Oscillation (AMO) ${ }^{1}$ explains a high percentage of the variability in ${ }^{\mathrm{Mdss} S S T}$ in the Iberian/Canary region, mostly in the central zone $\left(37.1^{\circ}\right.$ to $37.4^{\circ} \mathrm{N}$ ) in summer (Fig. 3a). The determination coefficients show close values throughout the whole region and small seasonal differences. This pattern is also observed in the NW African region, with some small seasonal modulations (Fig. 3a). Between 23.8 and $20^{\circ} \mathrm{N}$ the AMO had its main influence in the summer season, whereas, in the south $\left(14.3^{\circ}\right.$ to $\left.10.5^{\circ} \mathrm{N}\right)$, its effects also extended into the spring season. The AMO has no apparent effect over the variability in ${ }^{\mathrm{Mdss}} \mathrm{I}_{\mathrm{w}}$, except for a weak signal in the south of the NW African region $\left(16.2^{\circ}\right.$ to $\left.10.5^{\circ} \mathrm{N}\right)$ in autumn (not shown). Another index similar to the AMO and more appropriate for dealing with the variability in ${ }^{\text {Mdss }} I_{\mathrm{w}}$ is the North Atlantic Oscillation $(\mathrm{NAO})^{2}$, because it is formed via the difference between pressure systems. The NAO shows high correlation with ${ }^{\mathrm{Mdss}} I_{\mathrm{w}}$ in the Iberian/Canary region, mainly in spring and winter, and very low correlation in autumn and summer (Fig. 3b), which is more evident in the southern half of the region $\left(37.1^{\circ}\right.$ to $\left.27.6^{\circ} \mathrm{N}\right)$. The influence of the NAO index on ${ }^{\text {Mdss }} I_{\mathrm{W}}$ is also detected in the northern part of the NW African region down to $20^{\circ} \mathrm{N}$, where the determination coefficients abruptly descend to almost null values. The Eastern Atlantic Pattern (EA) ${ }^{3}$ is integral in explaining a significant portion of the variability in ${ }^{\text {Mdss }}$ SST throughout the Iberian/Canary region

\footnotetext{
1AMO: calculated from the Kalplan SST, available at: www. cdc.noaa.gov/data/timeseries/AMO/ (Enfield et al. 2001)

2NAO: first mode of sea-level pressure (SLP) variation in the North Atlantic (Jones et al. 1997)

${ }^{3}$ EA: second mode of SLP variation in the North Atlantic (Hurrell et al. 2003)
} 


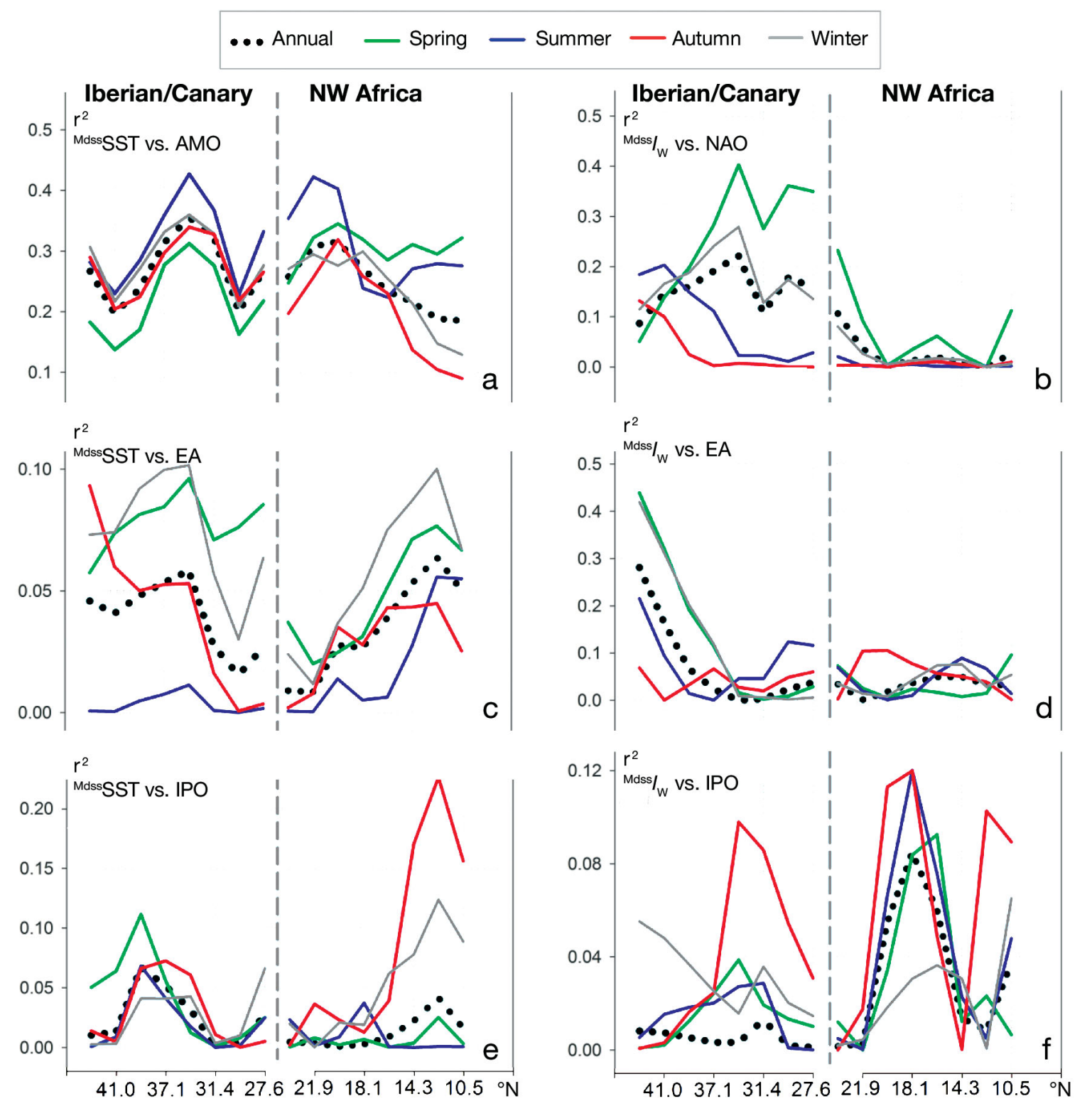

Fig. 3. Mdss SST and correlations with different climate indices (AMO: Atlantic Multidecadal Oscillation; NAO: North Atlantic Oscillation; EA: Eastern Atlantic Pattern; IPO: Interdecadal Pacific Oscillation) in the Iberian/Canary and NW Africa regions by season: spring (green line), summer (blue line), autumn (red line) and winter (grey line); and for the annual mean (black dotted line). (a) Correlation of ${ }^{\text {Mdss }}$ SST with AMO, (b) correlation of ${ }^{\text {Mdss }} I_{w}$ with NAO, (c, d) correlation of ${ }^{\text {Mdss }}$ SST and ${ }^{\text {Mdss }} I_{\mathrm{w}}$ with EA and (e, f) correlation of ${ }^{\mathrm{Mdss}} \mathrm{SST}$ and ${ }^{\mathrm{Mdss}} I_{\mathrm{w}}$ with IPO

(Fig. 3c), mainly in spring and winter, but with a lower percentage explained than with the AMO. In the NW African region, the EA plays a stronger role in winter and a minor role in spring, but mainly in the southern half of the zones $\left(18.1-10.5^{\circ} \mathrm{N}\right)$. The EA index presents a very high correlation with ${ }^{\mathrm{Mdss}} \mathrm{I}_{\mathrm{w}}$ in the northern half of the Iberian/Canary region $\left(42.9^{\circ}\right.$ to $\left.37.1^{\circ} \mathrm{N}\right)$, reaching $\mathrm{r}^{2}=0.43$ at $42.9^{\circ} \mathrm{N}$, and, again, spring and winter show the highest determination coefficients (Fig. 3c,d). The correlation of EA with ${ }^{\text {Mdss }} I_{\mathrm{w}}$ is less relevant in the NW
African region. The highest correlation is found in autumn in the northern half of the region $\left(21.9^{\circ}\right.$ to $\left.18.1^{\circ} \mathrm{N}\right)$, whereas in the southern half the EA explains most of the variability in winter and summer. The Interdecadal Pacific Oscillation (IPO) $)^{4}$ explains a good percentage of the variability in ${ }^{M d s}$ SST in the north of the Iberian/

4IPO: given by the Met Office's SST analysis and an almost independent night marine air temperature analysis (Parker et al. 2007) 
Canary region in spring $\left(42.9^{\circ}\right.$ to $\left.39^{\circ} \mathrm{N}\right)$ and less in the central zones in autumn $\left(37.1\right.$ and $\left.33.3^{\circ} \mathrm{N}\right)$. High values of the determination coefficient were also obtained in autumn in the southern zones of the NW African region $\left(14.3^{\circ}\right.$ to $\left.10.5^{\circ} \mathrm{N}\right)$, achieving a maximum value of $\mathrm{r}^{2} \approx$ 0.22 at $12.4^{\circ} \mathrm{N}$ (Fig. 3e). The percentage of variability in ${ }^{\text {Mdss }} I_{\mathrm{w}}$ explained by the IPO in the Iberian/Canary region is relatively high in the southern half of the region $\left(33.3^{\circ}\right.$ to $\left.27.6^{\circ} \mathrm{N}\right)$ in autumn, but with descending values southward (Fig. 3f). The autumn season is also the one presenting the highest determination coefficients in the correlation with ${ }^{\text {Mdss }} I_{\mathrm{w}}$ in the central and southern zones of the NW African region $\left(20^{\circ}\right.$ to $18.1^{\circ} \mathrm{N}$ and $12.4^{\circ}$ to $10.5^{\circ} \mathrm{N}$, respectively).

A significant correlation was found between ${ }^{\text {dss }}$ SST and ${ }^{\mathrm{dss}} I_{\mathrm{w}}$, with values varying specifically according to the season and the geographical zone. This could be due to differences in the location of the grid nodes with respect to the spreading jets of coastal upwelling. The sub- and mesoscale variability within the upwelling systems produces filaments that extend 100s of kilometres offshore and which are associated with differences in shelf width and/or the presence of major capes. Despite these results, the long-term trends found in each region suggest that the climatic mode variability has a strong influence on the variability of coastal upwelling and not only the increase of land-ocean pressure differences, as Bakun proposed. The influence of the NAO index is well documented, and the effect on upwelling systems in the East Atlantic has been pointed out by Belkin (2009) and Pérez et al. (2010). In fact, the important correlations found here of ${ }^{\text {Mdss }} \mathrm{SST}$ and ${ }^{\mathrm{Mdss}} I_{\mathrm{w}}$ with the NAO and EA in the Iberian/Canary and NW African regions sustain the noticeable weakening of upwelling-favourable winds for the L4D period.

\section{SUMMARY AND CONCLUSIONS}

A general weakening in upwelling intensity is shown in the Iberian/Canary region that can be extended southward into the NW African region. In some zones, the general warming observed in the Iberian/ Canary region exceeds mean oceanic values $\left(0.24^{\circ} \mathrm{C}\right.$ decade $^{-1}$; Gómez-Gesteira et al. 2008b), which suggests additional warming caused by the weakening in upwelling intensity. A warming trend is also observed in the NW African region. The trends observed in the Iberian/Canary and NW African regions are more prominent when only the last 4 decades are considered. These trends show different intensities when analyzing each season separately. Winter and autumn seasons show the most defined trends for ${ }^{\text {dss }} \mathrm{SST}$, and mainly winter, for ${ }^{d s s} I_{\mathrm{w}}$ in both the Iberian/Canary and NW African regions. The comparative study for the northern hemisphere does not exhibit clear similarities. The California region does not show any clear trend in ${ }^{\mathrm{dss}} I_{\mathrm{w}}$, but a cooling trend is obtained in most of the zones in the region. Nevertheless, in the last 4 decades, a warming value less than the global mean is obtained for this region. Analyses of the EBUEs in the southern hemisphere also provide results different from those obtained for the Iberian/Canary and NW African regions. In the Benguela region, an enhancement of $I_{\mathrm{w}}$ in the central zones, together with a slight warming trend, can be observed in some zones of the region, in agreement with Bakun's scheme, but not at the northern and southern limits, where the warming is accompanied by a decrease in upwelling intensity. The Peru region shows a weakening in upwelling intensity accompanied by a slight warming or even cooling trend in the period 1948-2009. When the last 4 decades are considered, a cooling trend is observed in the central and northern zones of the Peru region.

${ }^{\mathrm{dss}} I_{\mathrm{w}}$ correlates with ${ }^{\mathrm{dss}} \mathrm{SST}$ values mainly in winter and summer for the Iberian/Canary region and in winter and spring for the NW African region. The high correlation observed in the Cape Ghir zone $\left(31.4^{\circ} \mathrm{N}\right)$ is notable and is probably related to the interaction between the mesoscale variability inherent in upwelling systems and coast irregularities. The NAO and EA can be used as prediction indices for ${ }^{\text {Mdss }} I_{\mathrm{W}}$, primarily in winter and spring and for the northern (EA) and central-southern (NAO) parts of the Iberian/Canary region. The NAO also has some influence in the northern zones of the NW African region. The AMO, EA and IPO influence the variability in ${ }^{\text {Mdss }}$ SST. The AMO presents higher correlations than the other indices, mainly in summer, but only for the central zones of the Iberian/Canary region and for the northern zones of the NW African region. The variability in Mdss SST in the southern zones of the NW African region is influenced to a great extent by the modulation of the IPO, but only in autumn. The EA has a relatively weak influence in winter and spring for the central zones of the Iberian/ Canary region and for the southern zones of the NW African region. The influence of IPO in spring in the north-central zones of the Iberian/Canary region and in winter in the southern zones of the NW African region is very similar to that of the EA.

These overall results point out the differences in the variability in ${ }^{\mathrm{dss}} \mathrm{I}_{\mathrm{w}}$ and ${ }^{\mathrm{ds}} \mathrm{SST}$ throughout the different seasons of the year. The trends associated with each variable are also different in each season and can also vary according to the period of time analyzed. Climate indices are of great help in understanding the longterm trends and variability in ${ }^{d s s} I_{\mathrm{w}}$ and ${ }^{d s s} S S T$, which are not only affected by increases in land-ocean pressure differences, as a direct consequence of global warming, but also by some climatic modulations. 
Acknowledgements. The authors thank 2 anonymous reviewers for comments that contributed to the improvement of the manuscript. This study was partially funded by the Xunta de Galiza Research Project M4AO (PGIDIT07PXIB402153PR) and CAIBEX (CTM2007-66408-C02/MAR). P.C.P. was funded by the Xunta de Galicia Project (08MMA014402PR).

\section{LITERATURE CITED}

Arístegui J, Sangrá P, Hernández-León S, Cantón M, Hernández-Guerra A, Kerling JL (1994) Island-induced eddies in the Canary Islands and Canary Current upwelling. DeepSea Res I 41:1509-1525

Arístegui J, Álvarez-Salgado XA, Barton ED, Figueiras FG, Hernández-León S, Roy C, Santos AMP (2004) Oceanography and fisheries of the Canary Current/Iberian region of the eastern North Atlantic (18a, E). In: Robinson AR, Kenneth HB (eds) The sea, Vol 14. President and Fellows of Harvard College, Cambridge, MA

Arístegui J, Barton ED, Álvarez-Salgado XA, Santos AMP and others (2009) Sub-regional ecosystem variability in the Canary Current upwelling. Prog Oceanogr 83:33-48

Bakun A (1973) Coastal upwelling indices, west coast of North America 1946-1971. NOAA Tech Rep NMFS SSRF671

Bakun A (1990) Global climate change and intensification of coastal upwelling. Science 247:198-201

Bakun A, Field DB, Redondo-Rodríguez A, Weeks SJ (2009) Greenhouse gas, upwelling-favourable winds, and the future of coastal ocean upwelling ecosystems. Glob Change Biol 16:1213-1228

Barth JA, Menge BA, Lubchenco J, Chan F and others (2007) Delayed upwelling alters nearshore coastal ocean ecosystem in the northern California current. Proc Natl Acad Sci USA 104:3719-3724

Barton ED (1998) Eastern boundary of the North Atlantic: Northwest Africa and Iberia. Coastal segment (18, E). In: Robinson A, Brink KH (eds) The sea, Vol 11. John Wiley, New York, p 633-657

Belkin IM (2009) Rapid warming of large marine ecosystems. Prog Oceanogr 81:207-213

> Chavez FP, Messié M (2009) A comparison of eastern boundary upwelling ecosystems. Prog Oceanogr 83:80-96

Chavez FP, Messié M, Pennington JT (2010) Marine primary production in relation to climate variability change. Annu Rev Mar Sci 3:227-260

> Di Lorenzo E, Miller AJ, Schneider N, McWilliams JC (2005) The warming of the California current system: dynamics and ecosystem implications. J Phys Oceanogr 35:336-362

Enfield DB, Mestas-Nunez AM, Trimble PJ (2001) The Atlantic multidecadal oscillation and its relation to rainfall and river flows in the continental U.S. Geophys Res Lett 28:2077-2080

Gómez-Gesteira M, deCastro M, Álvarez I, Lorenzo MN, Gesteira JLG, Crespo AJC (2008a) Spatio-temporal upwelling trends along the Canary Upwelling System (19672006). In: Trends and directions in climate research. Ann NY Acad Sci 1146:320-337

Gómez-Gesteira M, deCastro M, Álvarez I, Gesteira JLG (2008b) Coastal sea surface temperature warming trend along the continental part of the Atlantic Arc (1985-2005). J Geophys Res 113:C04010. doi:10.1029/2007JC004315
Gregg WW, Casey NW, McClain CR (2005) Recent trends in global ocean chlorophyll. Geophys Res Lett 32:L03606. doi:10.1029/2004GL021808

Hagen E, Zulicke C, Feistel R (1996) Near-surface structures in the Cape Ghir filament off Morocco. Oceanol Acta 19: 577-598

> Hines KM, Bromwich DH, Marshall GJ (2000) Artificial surface pressure trends in the NCEP-NCAR reanalysis over the Southern Ocean and Antarctica. J Clim 13:3940-3952

Hurrell JW, Kushnir Y, Ottersen G, Visbeck M (2003) An overview of the North Atlantic Oscillation. In: The North Atlantic Oscillation: climatic significance and environmental impact. Geophy Monogr 134

> Jones PD, Jónsson T, Wheeler D (1997) Extension to the North Atlantic Oscillation using early instrumental pressure observations from Gibraltar and South-West Iceland. Int J Climatol 17:1433-1450

Kalnay E, Kanamitsu M, Kistler R (1996) The NCEP/NCAR 40-year reanalysis project. Bull Am Meteorol Soc 77: $437-470$

Lemos RT, Pires HO (2004) The upwelling regime off the west Portuguese coast, 1941-2000. Int J Climatol 24:511-524

> Lemos RT, Sansó B (2006) Spatio-temporal variability of ocean temperature in the Portugal Current System. J Geophys Res 111:C04010. doi:10.1029/2005JC003051

Mathieu PP, Sutton RT, Dong BW, Collins M (2004) Predictability of winter climate over the North Atlantic European region during ENSO events. J Clim 17:1953-1974

McGregor HV, Dima M, Fischer HW, Mulitza S (2007) Rapid 20th-century increase in coastal upwelling off Northwest Africa. Science 315:637-639

> Mendelssohn R, Schwing FB (2002) Common and uncommon trends in SST and wind stress in the California and PeruChile current systems. Prog Oceanogr 53:141-162

Parker D, Folland C, Scaife A, Knight J, Colman A, Baines P, Dong B (2007) Decadal to multidecadal variability and the climate change background. J Geophys Res 112:D18115. doi:10.1029/2007JD008411

> Pauly D, Christensen V (1995) Primary production required to sustain global fisheries. Nature 374:255-257

> Pérez F, Padín XA, Pazos Y, Gilcoto M and others (2010) Plankton response to weakening of the Iberian coastal upwelling. Glob Change Biol 16:1258-1267

Schwing FB, Mendelssohn R (1997) Increased coastal upwelling in the California Current System. J Geophys Res 102(C2):3421-3438

Schwing FB, Parrish R, Mendelssohn R (1998) Recent trends in the spatial structure of wind forcing and SST in the California Current System. In: Duran MH, Mendelssohn R, Cury P, Roy C, Pauly D (eds) Global versus local changes in upwelling systems. Proc 1st Int GEOS Workshop. ORSTOM, Paris, p 79-100

Snyder MA, Sloan LC, Diffenbaugh NS, Bell JL (2003) Future climate change and upwelling in the California Current. Geophys Res Lett 30:1823-1826 doi:10.1029/2003GL 017647

Tomczak M, Godfrey JS (2003) Regional oceanography: an introduction, 2nd edn. Daya Publishing House, Delhi. Available at: www.es.flinders.edu.au/ mattom/regoc/pdfversion. html

Wooster WS, Bakun A, McLain DR (1976) The seasonal upwelling cycle along the eastern boundary of the North Atlantic. J Mar Res 34:131-140 
Appendix

Table A1. Long-term variability in sea-surface temperature (SST) and the upwelling index $\left(I_{\mathrm{w}}\right)\left[\Gamma(\mathrm{SST})\right.$ and $\left.\Gamma\left(I_{\mathrm{w}}\right)\right]$ and correlation between the deseasonalized series $\left(\delta^{\mathrm{dss}} I_{\mathrm{w}} / \delta^{\mathrm{dss}} \mathrm{SST}\right.$ ) in the Iberian/Canary region. The statistic analysis (regression coefficient and p-level) of the datasets for the whole period $(1948-2009 ; n=90580)$ and for the last 4 decades (L4D) are shown for each zone (latitudes of NCEP grid nodes). Bold values are not statistically significant

\begin{tabular}{|c|c|c|c|c|c|c|c|c|c|c|}
\hline Zone & Period & $\Gamma(\mathrm{SST})$ & $\mathrm{r}$ & $\mathrm{p}$ & $\Gamma\left(I_{\mathrm{w}}\right)$ & $\mathrm{r}$ & $\mathrm{p}$ & $\delta^{\mathrm{dss}} I_{\mathrm{w}} / \delta^{\mathrm{dss}} \mathrm{SST}$ & $\mathrm{r}$ & $\mathrm{p}$ \\
\hline \multicolumn{11}{|c|}{ Iberian/Canary } \\
\hline \multirow[t]{2}{*}{$42.9^{\circ} \mathrm{N}$} & Whole & $0.078 \pm 0.001$ & 0.26 & 0.0002 & $-18 \pm 2$ & -0.04 & 0.008 & $-97 \pm 5$ & -0.06 & 0.003 \\
\hline & L4D & $0.261 \pm 0.002$ & 0.50 & 0.0001 & $-37 \pm 3$ & -0.05 & 0.007 & $-90 \pm 6$ & -0.06 & 0.004 \\
\hline \multirow[t]{2}{*}{$41.0^{\circ} \mathrm{N}$} & Whole & $0.063 \pm 0.001$ & 0.20 & 0.0003 & $-13 \pm 1$ & -0.03 & 0.011 & $-94 \pm 4$ & -0.07 & 0.002 \\
\hline & L4D & $0.224 \pm 0.002$ & 0.40 & 0.0001 & $-22 \pm 3$ & -0.03 & 0.015 & $-81 \pm 5$ & -0.07 & 0.004 \\
\hline \multirow[t]{2}{*}{$39.0^{\circ} \mathrm{N}$} & Whole & $0.135 \pm 0.001$ & 0.37 & 0.0001 & $-8 \pm 1$ & -0.02 & 0.029 & $-85 \pm 4$ & -0.07 & 0.002 \\
\hline & L4D & $0.347 \pm 0.002$ & 0.54 & $<0.0001$ & $-6 \pm 3$ & -0.01 & 0.173 & $-69 \pm 4$ & -0.07 & 0.004 \\
\hline \multirow[t]{2}{*}{$37.1^{\circ} \mathrm{N}$} & Whole & $0.134 \pm 0.001$ & 0.39 & 0.0001 & $-5 \pm 1$ & -0.01 & 0.058 & $-80 \pm 4$ & -0.07 & 0.002 \\
\hline & L4D & $0.359 \pm 0.002$ & 0.59 & $<0.0001$ & $2 \pm 3$ & 0.00 & 0.912 & $-63 \pm 4$ & -0.06 & 0.005 \\
\hline \multirow[t]{2}{*}{$33.3^{\circ} \mathrm{N}$} & Whole & $0.099 \pm 0.001$ & 0.32 & 0.0001 & $-14 \pm 1$ & -0.04 & 0.008 & $-71 \pm 4$ & -0.06 & 0.003 \\
\hline & L4D & $0.299 \pm 0.002$ & 0.56 & $<0.0001$ & $-15 \pm 2$ & -0.03 & 0.024 & $-59 \pm 4$ & -0.06 & 0.006 \\
\hline \multirow[t]{2}{*}{$31.4^{\circ} \mathrm{N}$} & Whole & $0.038 \pm 0.001$ & 0.13 & 0.0007 & $-28 \pm 2$ & -0.06 & 0.003 & $-143 \pm 5$ & -0.09 & 0.001 \\
\hline & L4D & $0.193 \pm 0.002$ & 0.38 & 0.0001 & $-35 \pm 3$ & -0.05 & 0.007 & $-134 \pm 6$ & -0.09 & 0.002 \\
\hline \multirow[t]{2}{*}{$29.5^{\circ} \mathrm{N}$} & Whole & $0.030 \pm 0.001$ & 0.10 & 0.0011 & $-1 \pm 1$ & -0.00 & 0.601 & $-37 \pm 3$ & -0.04 & 0.006 \\
\hline & L4D & $0.141 \pm 0.002$ & 0.27 & 0.0002 & $9 \pm 2$ & 0.02 & 0.035 & $-26 \pm 3$ & -0.03 & 0.015 \\
\hline \multirow[t]{2}{*}{$27.6^{\circ} \mathrm{N}$} & Whole & $0.081 \pm 0.001$ & 0.26 & 0.0002 & $2 \pm 1$ & 0.00 & 0.361 & $-81 \pm 4$ & -0.07 & 0.003 \\
\hline & L4D & $0.239 \pm 0.002$ & 0.43 & 0.0001 & $15 \pm 2$ & 0.03 & 0.025 & $-65 \pm 4$ & -0.06 & 0.005 \\
\hline \multicolumn{11}{|c|}{ NW Africa } \\
\hline \multirow{2}{*}{$23.8^{\circ} \mathrm{N}$} & Whole & $0.021 \pm 0.001$ & 0.07 & 0.0020 & $11 \pm 2$ & 0.02 & 0.022 & $-160 \pm 5$ & -0.10 & 0.001 \\
\hline & L4D & $0.163 \pm 0.002$ & 0.31 & 0.0002 & $-2 \pm 3$ & -0.00 & 0.845 & $-146 \pm 6$ & -0.10 & 0.002 \\
\hline \multirow[t]{2}{*}{$21.9^{\circ} \mathrm{N}$} & Whole & $0.024 \pm 0.001$ & 0.07 & 0.0020 & $-11 \pm 2$ & -0.02 & 0.020 & $-120 \pm 5$ & -0.09 & 0.001 \\
\hline & L4D & $0.213 \pm 0.002$ & 0.36 & 0.0001 & $-23 \pm 3$ & -0.03 & 0.016 & $-112 \pm 5$ & -0.09 & 0.002 \\
\hline \multirow[t]{2}{*}{$20.0^{\circ} \mathrm{N}$} & Whole & $0.102 \pm 0.001$ & 0.24 & 0.0002 & $-46 \pm 2$ & -0.10 & 0.001 & $-53 \pm 4$ & -0.05 & 0.004 \\
\hline & L4D & $0.362 \pm 0.003$ & 0.46 & 0.0001 & $-47 \pm 3$ & -0.07 & 0.004 & $-43 \pm 4$ & -0.05 & 0.007 \\
\hline \multirow[t]{2}{*}{$18.1^{\circ} \mathrm{N}$} & Whole & $0.054 \pm 0.001$ & 0.13 & 0.0006 & $-64 \pm 2$ & -0.14 & 0.001 & $-44 \pm 4$ & -0.04 & 0.008 \\
\hline & L4D & $0.232 \pm 0.003$ & 0.32 & 0.0001 & $-62 \pm 3$ & -0.09 & 0.002 & $-40 \pm 4$ & -0.04 & 0.010 \\
\hline \multirow[t]{2}{*}{$16.2^{\circ} \mathrm{N}$} & Whole & $0.090 \pm 0.001$ & 0.22 & 0.0002 & $-57 \pm 2$ & -0.12 & 0.001 & $-65 \pm 4$ & -0.06 & 0.003 \\
\hline & L4D & $0.233 \pm 0.003$ & 0.33 & 0.0001 & $-53 \pm 3$ & -0.08 & 0.003 & $-46 \pm 4$ & -0.05 & 0.007 \\
\hline \multirow[t]{2}{*}{$14.3^{\circ} \mathrm{N}$} & Whole & $0.125 \pm 0.001$ & 0.29 & 0.0001 & $-34 \pm 1$ & -0.08 & 0.002 & $-77 \pm 3$ & -0.07 & 0.002 \\
\hline & L4D & $0.272 \pm 0.003$ & 0.37 & 0.0001 & $-41 \pm 3$ & -0.06 & 0.004 & $-61 \pm 4$ & -0.07 & 0.003 \\
\hline \multirow[t]{2}{*}{$12.4^{\circ} \mathrm{N}$} & Whole & $0.176 \pm 0.001$ & 0.38 & 0.0001 & $-7 \pm 1$ & -0.01 & 0.051 & $-62 \pm 3$ & -0.06 & 0.003 \\
\hline & L4D & $0.329 \pm 0.003$ & 0.41 & 0.0001 & $-41 \pm 3$ & -0.06 & 0.005 & $-60 \pm 4$ & -0.07 & 0.003 \\
\hline \multirow[t]{2}{*}{$10.5^{\circ} \mathrm{N}$} & Whole & $0.138 \pm 0.001$ & 0.36 & 0.0001 & $-24 \pm 1$ & -0.07 & 0.002 & $-52 \pm 3$ & -0.06 & 0.003 \\
\hline & L4D & $0.263 \pm 0.003$ & 0.39 & 0.0001 & $-29 \pm 2$ & -0.06 & 0.005 & $-34 \pm 3$ & -0.05 & 0.008 \\
\hline \multicolumn{11}{|c|}{ California } \\
\hline $44.8^{\circ} \mathrm{N}$ & Whole & $-0.011 \pm 0.001$ & -0.03 & 0.011 & $-2 \pm 2$ & -0.00 & 0.38 & $-63 \pm 4$ & -0.05 & 0.005 \\
\hline & L4D & $0.035 \pm 0.003$ & 0.06 & 0.005 & $0 \pm 3$ & 0.00 & 1.00 & $-59 \pm 5$ & -0.05 & 0.007 \\
\hline $42.9^{\circ} \mathrm{N}$ & Whole & $-0.001 \pm 0.001$ & -0.00 & 0.610 & $-2 \pm 2$ & -0.00 & 0.67 & $-81 \pm 4$ & -0.06 & 0.003 \\
\hline & L4D & $0.086 \pm 0.003$ & 0.13 & 0.001 & $1 \pm 3$ & 0.00 & 1.00 & $-76 \pm 5$ & -0.06 & 0.004 \\
\hline $41.0^{\circ} \mathrm{N}$ & Whole & $-0.011 \pm 0.001$ & -0.03 & 0.014 & $1 \pm 2$ & 0.00 & 0.84 & $-102 \pm 5$ & -0.08 & 0.002 \\
\hline & L4D & $0.081 \pm 0.003$ & 0.12 & 0.001 & $-1 \pm 4$ & -0.00 & 1.00 & $-100 \pm 5$ & -0.08 & 0.003 \\
\hline $39.0^{\circ} \mathrm{N}$ & Whole & $-0.101 \pm 0.001$ & -0.23 & $<0.001$ & $-3 \pm 1$ & -0.01 & 0.17 & $-54 \pm 3$ & -0.07 & 0.002 \\
\hline & L4D & $-0.055 \pm 0.003$ & -0.07 & 0.003 & $-18 \pm 2$ & -0.03 & 0.017 & $-57 \pm 3$ & -0.07 & 0.003 \\
\hline $37.1^{\circ} \mathrm{N}$ & Whole & $-0.058 \pm 0.001$ & -0.14 & 0.001 & $6 \pm 1$ & 0.02 & 0.044 & $-73 \pm 3$ & -0.07 & 0.002 \\
\hline & L4D & $-0.055 \pm 0.003$ & -0.08 & 0.003 & $-5 \pm 3$ & -0.01 & 0.26 & $-76 \pm 4$ & -0.08 & 0.003 \\
\hline $35.2^{\circ} \mathrm{N}$ & Whole & $0.012 \pm 0.001$ & 0.03 & 0.012 & $18 \pm 1$ & 0.05 & 0.004 & $-39 \pm 3$ & -0.05 & 0.005 \\
\hline & L4D & $0.013 \pm 0.003$ & 0.02 & 0.045 & $12 \pm 2$ & 0.02 & 0.033 & $-49 \pm 3$ & -0.06 & 0.004 \\
\hline $33.3^{\circ} \mathrm{N}$ & Whole & $0.018 \pm 0.001$ & 0.04 & 0.006 & $9 \pm 1$ & 0.04 & 0.008 & $-4 \pm 2$ & -0.01 & 0.190 \\
\hline & L4D & $-0.002 \pm 0.003$ & -0.00 & 0.903 & $-8 \pm 2$ & -0.02 & 0.049 & $-12 \pm 2$ & -0.02 & 0.042 \\
\hline
\end{tabular}


Table A1. (continued)

\begin{tabular}{|c|c|c|c|c|c|c|c|c|c|c|}
\hline Zone & Period & $\Gamma(\mathrm{SST})$ & $\mathrm{r}$ & $\mathrm{p}$ & $\Gamma\left(I_{\mathrm{w}}\right)$ & $\mathrm{r}$ & $\mathrm{p}$ & $\delta^{\mathrm{dss}} I_{\mathrm{w}} / \delta^{\mathrm{dss}} \mathrm{SST}$ & $\mathrm{r}$ & $\mathrm{p}$ \\
\hline \multicolumn{11}{|c|}{ Benguela } \\
\hline \multirow[t]{2}{*}{$16.2^{\circ} \mathrm{S}$} & Whole & $0.111 \pm 0.002$ & 0.21 & $<0.001$ & $-52 \pm 2$ & -0.10 & 0.001 & $45 \pm 3$ & 0.05 & 0.005 \\
\hline & L4D & $0.237 \pm 0.004$ & 0.26 & $<0.001$ & $28 \pm 3$ & 0.04 & 0.011 & $56 \pm 3$ & 0.07 & 0.003 \\
\hline \multirow[t]{2}{*}{$18.1^{\circ} \mathrm{S}$} & Whole & $0.095 \pm 0.001$ & 0.21 & $<0.001$ & $-41 \pm 2$ & -0.06 & 0.003 & $51 \pm 5$ & 0.04 & 0.008 \\
\hline & L4D & $0.201 \pm 0.003$ & 0.25 & $<0.001$ & $57 \pm 4$ & 0.06 & 0.005 & $68 \pm 5$ & 0.06 & 0.005 \\
\hline \multirow[t]{2}{*}{$20.0^{\circ} \mathrm{S}$} & Whole & $0.026 \pm 0.001$ & 0.07 & 0.002 & $-2 \pm 2$ & -0.00 & 0.642 & $40 \pm 5$ & 0.03 & 0.016 \\
\hline & L4D & $0.048 \pm 0.002$ & 0.08 & 0.003 & $65 \pm 4$ & 0.07 & 0.003 & $49 \pm 6$ & 0.03 & 0.015 \\
\hline \multirow[t]{2}{*}{$21.9^{\circ} \mathrm{S}$} & Whole & $-0.015 \pm 0.001$ & -0.04 & 0.006 & $5 \pm 1$ & 0.01 & 0.049 & $27 \pm 3$ & 0.03 & 0.013 \\
\hline & L4D & $0.013 \pm 0.002$ & 0.02 & 0.033 & $37 \pm 2$ & 0.07 & 0.003 & $32 \pm 4$ & 0.04 & 0.012 \\
\hline \multirow[t]{2}{*}{$23.8^{\circ} \mathrm{S}$} & Whole & $0.031 \pm 0.001$ & 0.09 & 0.001 & $10 \pm 2$ & 0.02 & 0.027 & $5 \pm 5$ & 0.00 & 0.621 \\
\hline & L4D & $0.066 \pm 0.002$ & 0.12 & 0.001 & $98 \pm 3$ & 0.12 & 0.001 & $38 \pm 6$ & 0.03 & 0.025 \\
\hline \multirow[t]{2}{*}{$25.7^{\circ} \mathrm{S}$} & Whole & $0.073 \pm 0.001$ & 0.23 & $<0.001$ & $21 \pm 2$ & 0.04 & 0.008 & $-28 \pm 6$ & -0.02 & 0.044 \\
\hline & L4D & $0.105 \pm 0.002$ & 0.21 & $<0.001$ & $100 \pm 4$ & 0.12 & 0.001 & $11 \pm 7$ & 0.01 & 0.373 \\
\hline \multirow[t]{2}{*}{$27.6^{\circ} \mathrm{S}$} & Whole & $0.108 \pm 0.001$ & 0.35 & $<0.001$ & $5 \pm 1$ & 0.01 & 0.071 & $-7 \pm 5$ & -0.01 & 0.350 \\
\hline & L4D & $0.191 \pm 0.002$ & 0.37 & $<0.001$ & $33 \pm 3$ & 0.05 & 0.008 & $15 \pm 6$ & 0.01 & 0.129 \\
\hline \multirow[t]{2}{*}{$29.5^{\circ} \mathrm{S}$} & Whole & $0.074 \pm 0.001$ & 0.25 & $<0.001$ & $-3 \pm 1$ & -0.01 & 0.110 & $-23 \pm 4$ & -0.02 & 0.024 \\
\hline & L4D & $0.163 \pm 0.002$ & 0.32 & $<0.001$ & $-8 \pm 2$ & -0.01 & 0.076 & $-17 \pm 4$ & -0.02 & 0.055 \\
\hline \multicolumn{11}{|l|}{ Peru } \\
\hline \multirow[t]{2}{*}{$6.7^{\circ} \mathrm{S}$} & Whole & $0.045 \pm 0.003$ & 0.06 & 0.003 & $-48 \pm 1$ & -0.11 & 0.001 & $33 \pm 2$ & 0.06 & 0.003 \\
\hline & L4D & $-0.006 \pm 0.006$ & -0.00 & 0.604 & $-9 \pm 3$ & -0.01 & 0.074 & $47 \pm 2$ & 0.10 & 0.002 \\
\hline \multirow[t]{2}{*}{$8.6^{\circ} \mathrm{S}$} & Whole & $0.015 \pm 0.002$ & 0.02 & 0.024 & $-98 \pm 2$ & -0.15 & 0.001 & $90 \pm 3$ & 0.10 & 0.001 \\
\hline & L4D & $-0.076 \pm 0.005$ & -0.06 & 0.004 & $-68 \pm 4$ & -0.07 & 0.004 & $111 \pm 3$ & 0.13 & 0.001 \\
\hline \multirow[t]{2}{*}{$10.5^{\circ} \mathrm{S}$} & Whole & $0.036 \pm 0.002$ & 0.05 & 0.004 & $-40 \pm 1$ & -0.11 & 0.001 & $54 \pm 2$ & 0.10 & 0.001 \\
\hline & L4D & $-0.028 \pm 0.005$ & -0.02 & 0.032 & $-34 \pm 2$ & -0.06 & 0.005 & $71 \pm 2$ & 0.15 & 0.001 \\
\hline \multirow[t]{2}{*}{$12.4^{\circ} \mathrm{S}$} & Whole & $0.035 \pm 0.002$ & 0.06 & 0.003 & $-83 \pm 2$ & -0.14 & 0.001 & $103 \pm 3$ & 0.10 & 0.001 \\
\hline & L4D & $-0.024 \pm 0.004$ & -0.02 & 0.029 & $-107 \pm 4$ & -0.11 & 0.001 & $136 \pm 4$ & 0.15 & 0.001 \\
\hline \multirow[t]{2}{*}{$14.3^{\circ} \mathrm{S}$} & Whole & $0.127 \pm 0.002$ & 0.22 & $<0.001$ & $-13 \pm 1$ & -0.04 & 0.009 & $20 \pm 2$ & 0.03 & 0.012 \\
\hline & L4D & $0.168 \pm 0.004$ & 0.17 & 0.001 & $9 \pm 2$ & 0.02 & 0.062 & $37 \pm 2$ & 0.06 & 0.004 \\
\hline \multirow[t]{2}{*}{$16.2^{\circ} \mathrm{S}$} & Whole & $0.186 \pm 0.002$ & 0.37 & $<0.001$ & $1 \pm 1$ & 0.00 & 0.759 & $38 \pm 2$ & 0.07 & 0.002 \\
\hline & L4D & $0.251 \pm 0.003$ & 0.30 & $<0.001$ & $42 \pm 2$ & 0.10 & 0.002 & $55 \pm 2$ & 0.10 & 0.002 \\
\hline
\end{tabular}

